\title{
The use of ketogenic diets in cancer patients: a systematic review
}

\author{
Maximilian Römer ${ }^{1}\left[\right.$. Jennifer Dörfler ${ }^{1}\left(\mathbb{0}\right.$. Jutta Huebner ${ }^{1}$
}

Received: 9 February 2021 / Accepted: 26 March 2021 / Published online: 3 April 2021

(c) The Author(s) 2021

\begin{abstract}
Ketogenic diets are a widely known, yet controversial treatment for cancer patients. In this review, we summarize the clinical evidence for anti-tumor effects, as well as the effects on anthropometry, quality of life, adverse events and adherence in cancer patients. In April 2019, a systematic search was conducted searching five electronic databases (EMBASE, Cochrane, PsychInfo, CINAHL and Medline) to find studies analyzing the use, effectiveness and potential harm of a ketogenic diet in cancer patients of any age as sole or complementary therapy. From all 19.211 search results, 46 publications concerning 39 studies with 770 patients were included in this systematic review. The therapy concepts included all forms of diets with reduced carbohydrate intake, that aimed to achieve ketosis for patients with different types of cancer. Most studies had a low quality, high risk of bias and were highly heterogeneous. There was no conclusive evidence for anti-tumor effects or improved OS. The majority of patients had significant weight loss and mild to moderate side effects. Adherence to the diet was rather low in most studies. Due to the very heterogeneous results and methodological limitations of the included studies, clinical evidence for the effectiveness of ketogenic diets in cancer patients is still lacking.
\end{abstract}

Keywords Humans $\cdot$ Metabolism $\cdot$ Ketogenic diet $\cdot$ Low-carbohydrate diet $\cdot$ Carbohydrate-restricted $\cdot$ Cancer

$\begin{array}{ll}\text { Abbreviations } \\ \text { KD } & \text { Ketogenic diet } \\ \text { RCT } & \text { Randomized controlled trial } \\ \text { CT } & \text { Controlled trial } \\ \text { PSADT } & \text { Prostate-specific antigen doubling time } \\ \text { PFS } & \text { Progression-free survival } \\ \text { PCS } & \text { Physical component summary } \\ \text { MCS } & \text { Mental component summary } \\ \text { SF-12 } & \text { Short Form (12) Health Survey } \\ \text { QoL } & \text { Quality of life } \\ \text { HNC } & \text { Head and neck cancer } \\ \text { FM } & \text { Fat mass } \\ \text { FFM } & \text { Fat-free mass } \\ \text { AE } & \text { Adverse events } \\ \text { SoC } & \text { Standard of care } \\ \text { DLT } & \text { Dose-limiting toxicity } \\ \text { CTCAE } & \text { NCI Common Terminology Criteria for } \\ & \text { Adverse Events } \\ \text { OS } & \text { Overall survival }\end{array}$

Maximilian Römer

maximilian.roemer@uni-jena.de

$1 \quad$ Klinik Für Innere Medizin II, Hämatologie Und Internistische Onkologie, Universitätsklinikum Jena, Am Klinikum 1, 07747 Jena, Germany

\section{Introduction}

Current cancer treatment is largely based on surgery, radiation and chemotherapy. Despite the advances in these fields and the implementation of targeted therapies and immune checkpoint inhibitors, many cancer patients still suffer from a poor prognosis and search for alternative or complementary treatments. Since there is a growing recognition of the impact of dietary interventions on human health [1], many cancer patients try to optimize their diet to improve their prognosis and reduce treatment-associated side effects [2].

For these patients and professionals alike, the ketogenic diet (KD) is compelling due to its success in treating epilepsy [3] and its theoretical foundation. The proposed antitumor effect relies on Warburg's observation, that cancer cells prefer anaerobic glycolysis, even in the presence of oxygen [4]. Further, cancer cells use glycolysis for rapid cell proliferation [5] and the formation of metastases [6]. Hence, KDs, which are high in fat and low in carbohydrates [7], try to reduce the amount of glucose in the body, that the cancer cells can utilize $[8,9]$. The exact ratio of macronutrients differs between the specific variations of this diet [10]. Probably, the most renown adaption of this diet is a 4:1 fat-to-carbohydrate + protein ratio [7]. Such an approach was used successfully in cellular and animal studies [11, 
12]. Nonetheless, there were also contradicting studies that showed that there are cancer cell lines, which can utilize fatty acids and ketone bodies [13-16].

Our aim in this review was to systematically assess whether the results from in vitro studies translated to clinical evidence of anti-tumor efficiency and further analyze the impact that a KD has on the quality of life and anthropometry of the patients.

\section{Method}

\section{Criteria for including and excluding studies in the review}

Inclusion and exclusion criteria are listed in Table 1 based on a PICO model. According to the recommendations of the Cochrane Effective Practice and Organization of Care (EPOC) systematic reviews, review and meta-analyses, randomized controlled studies (RCT), non-randomized controlled studies (CT), uncontrolled studies (process monitoring, uncontrolled before-after studies and time series analyses) and observational studies were included [17]. We additionally included case series and case studies, due to the low number of publications on this topic. Criteria for rejecting studies were primary prevention, gray literature, other publication types than primary investigation/report (e.g., comments, letters, abstracts) or precancerous conditions if the results of the patients with cancer were not reported separately. Additionally, studies were excluded if they reported no patient-centered outcomes (laboratory parameters, except PSA which was considered as a surrogate parameter for tumor progression of prostate cancer). Language restrictions were made to English and German.

\section{Study selection}

A systematic research was conducted using five databases (Medline (Ovid), CINAHL (EBSCO), EMBASE (Ovid), Cochrane CENTRAL and PsycINFO (EBSCO)) in April 2019. For each of these databases, a complex search strategy was developed, consisting of a combination of MeshTerms, keywords and text words in different spellings connected to cancer and ketogenic diets. The detailed search string is provided in online resource 1 . The search string was highly sensitive, since it was largely unrestricted by filters for study or publication type. After importing the search results into EndNote X9, all duplicates were removed and a title-abstract screening was carried out by two independent reviewers (MR, JD). In case of disagreement, consensus was made by discussion. After that, all full texts were retrieved and screened again independently by both reviewers. When title and abstract did not have sufficient information for screening purposes, a full-text copy was retrieved as well. Additionally, bibliography lists of all retrieved articles were manually screened for relevant studies. Such studies were included if they provided a comprehensive description of the study. The study flow during this process is presented in Fig. 1.

\section{Assessment of risk of bias and methodological quality}

All characteristics were assessed by two independent reviewers (MR, JD). In case of disagreement, a third reviewer was consulted ( $\mathrm{JH})$ and consensus was made by discussion.

Table 1 Inclusion and exclusion criteria based on a PICO model

\begin{tabular}{lll}
\hline PICO & Inclusion criteria & Exclusion criteria \\
\hline Patient & Cancer patients (all entities and stages) & $\begin{array}{l}\text { Patients with precancerous conditions or carcinoma in situ } \\
\text { Primary prevention } \\
\text { Preclinical studies }\end{array}$ \\
Intervention & Every intervention based on a ketogenic diet \\
& No restrictions regarding the type of KD, dose, mode of application & \\
& KD applied as sole or supplementary treatment \\
Comparison & All possible control groups (active control, placebo, standard/guide- \\
& line/usual care) & \\
Outcome & Mortality (overall survival) & \\
& Morbidity (progression-/disease-free interval, tumor response) & \\
& Patient-reported outcomes (i.e., quality of life or other important \\
psychological outcomes like psychological well-being, fatigue, as & \\
& well as physical and mental adverse effects) & \\
& Weight and body composition & \\
Toxicity and adverse events (CTCAE) & Gray literature (conference articles, abstracts, letters, ongo- \\
Others & Language: German and English & Full text not available in German or English \\
\hline
\end{tabular}


Fig. 1 Preferred reporting items for systematic reviews and meta-analyses flow chart displaying the study selection process

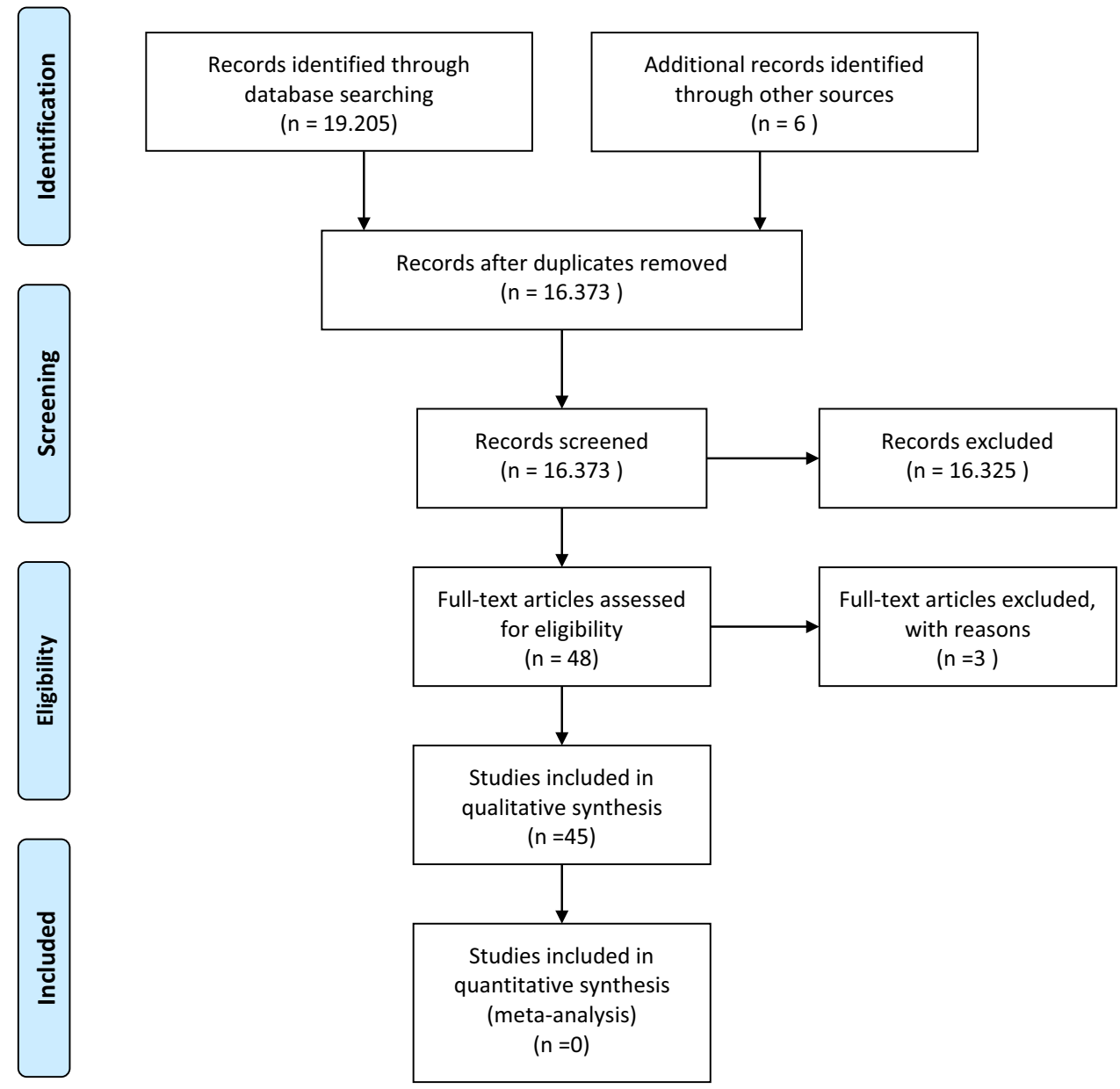

\section{Risk of bias and methodological quality}

The risk of bias of the included RCTs and CTs was analyzed with the SIGN-Checklist [18] for controlled trials version 2.0. The AMSTAR-2 instrument for systematic reviews was used for reviews and systematic reviews. Other study types were analyzed based on the Cochrane Risk of Bias tool [19]. Further, these studies were rated with the Oxford criteria. Additional criteria concerning methodology were size of population, application of power analysis, adequacy of statistical tests (e.g., control of premises or multiple testing) and selective outcome reporting (report of all assessed outcomes with specification of statistical data as the $p$-value) as well as possible conflicts of interest.

\section{Data synthesis}

No studies were suitable for a pooled analysis; hence, only a narrative analysis can be presented here.

\section{Data extraction}

Data extraction was performed by one reviewer (MR) and controlled by two independent reviewers (JD, JH). As a template for data extraction, the evidence tables from the national Guideline on Complementary and Alternative Medicine in Oncological Patients of the German Guideline Program in Oncology (https://www.leitlinienprogrammonkologie.de/english-language/) were used. Due to a large overlap in studies included in the systematic reviews, only the data from the individual studies, which were included in the systematic reviews, were extracted. Extraction was limited to data from primary literature and other sources, which provided a comprehensive description of the study, meeting the inclusion criteria. 


\section{Results}

The systematic search revealed 19.205 results. Six studies were added by hand search. At first, duplicates were removed leaving 16.373 studies. After screening title and abstract, 48 studies remained to complete review. Finally, 45 publications were analyzed in this review, including $5 \mathrm{SR}$, 1 review and additionally 5 publications on 3 RCTs, 2 controlled studies and 33 single-arm studies and case reports, presented in 32 publications. All in all, 765 patients were described in 39 publications.

\section{Characteristics of included studies}

Concerning the RCTs and CTs, 322 patients were included and 250 of them were analyzed, due to 72 drop-outs. The mean age of patients (only reported in 3 studies) ranged from 44.8 to 66.3 years and the range of age from 38 to 76 years (reported in 1 study). One publication only reported the median age, which was 72 years. A total of $156(62 \%)$ participants were female and 94 (38\%) were male. Concerning the studies with a fixed duration of intervention, the extent of the diet ranged from 3 to 6 months.

In the single-arm studies and case series, a total of 443 patients were included and analyzed. The age of the included patients ranged from 3 to 92 years. Information about the gender of the included patients could be obtained for 370 of the 443 patients. Out of these 370 participants, 184 (50\%) were female and 186 (50\%) were male. Duration of the dietary intervention in these studies reached from a single, $3 \mathrm{~h}$ long, application of parenteral nutrition [20] to a single case with more than 31 months of oral KD [21].

The KDs prescribed in the included studies varied extensively between studies (see Table 6 for details concerning the prescribed diets) were in most articles not described in adequate detail, and the majority did not utilize standardized dietary protocols. Furthermore, the methods used for assessing ketone body levels and diet compliance varied widely, with some studies not measuring them at all.

\section{Excluded studies}

A list of the studies excluded after full-text screening and the reasons for exclusion are presented in online resource 2 .

\section{Risk of bias in included studies}

The methodical quality of the included RCTs and CTs was rated according to the SIGN checklists [18], and the results are presented in Table 2. Other study types were analyzed based on the Cochrane Risk of Bias tool [22], with the results presented in Table 3. These studies were further rated based on the Oxford criteria. These results and additional comments on methodology are provided in Table 4.

\section{Efficacy of the ketogenic diet}

The study characteristics and all relevant results reported in the included RCTs and CTs are presented in Table 5. Similar information concerning the included single-arm studies and case reports is presented in Table 6.

\section{Survival and disease progression}

\section{Results from RCTs and CTs}

Overall survival was only analyzed in one RCT [23]. In this study, the overall survival (OS) for a subgroup of patients with neoadjuvant treatment for breast cancer was significantly higher in the intervention group $(p=0.04)$. However, no data for the entire study population are presented, which also consisted of patients with metastatic disease.

One RCT assessed the effects of the diet on prostatespecific antigen doubling time (PSADT) as a surrogate parameter for progression of disease [24]. Per protocol, there was no between-group difference concerning the PSADT $(p=0.446)$. Only in post hoc exploratory analysis with adjusting for multiple baseline covariates and proposed hemoconcentration, a significantly increased PSADT could be found.

\section{Results from single-arm studies and case reports}

Only five of these studies compared reported and expected survival, which was derived from historical controls [25-29]. In one study [25], two of the patients were analyzed and their survival was comparable with the expected survival, similar to another study where all of the different subgroups of patients had an OS in line with the historical controls [28]. Two other studies [26, 27] found a numerically better than expected survival. However, no statistical analysis was performed. One study, however, reported a lower-than-expected survival for the patients receiving a KD [29].

Another study compared the subgroup of patients, who received bevacizumab salvage treatment while on a KD with other patients treated with bevacizumab in the same hospital, who did not receive a KD. There was no difference in median progression-free survival (PFS) $(p=0.38)$ [30].

Even though most studies reported on tumor stability and progression, the results were highly heterogeneous and the tools and methods used for this assessment were only reported in a minority of them in adequate detail. Furthermore, there was no analysis for statistical significance of the findings. 
Table 2 Risk of bias in the included RCTs and CTs according to the SIGN checklist

\begin{tabular}{|c|c|c|c|c|}
\hline Reference & Study type & Standardized rating of risk of bias & Additional comments on methodology & $\begin{array}{l}\text { Evidence } \\
\text { level } \\
\text { (Oxford) }\end{array}$ \\
\hline Freedland et al. [24] & $\mathrm{RCT}$ & $\begin{array}{l}\text { Rating according to SIGN } \\
\text { Positive: } 4 \text { points } \\
\text { Uncertain: } 2 \text { points } \\
\text { Negative: } 3 \text { points } \\
\text { Overall quality: acceptable }\end{array}$ & $\begin{array}{l}\text { PRO: in accordance with the ethical guidelines of } \\
\text { the US Common Rule; randomization stratified by } \\
\text { center and BMI; compliance surveilled in arm A with } \\
\text { weekly urine ketone measurement; comprehensive } \\
\text { and adequate analysis including the most important } \\
\text { factors; power analysis } \\
\text { Contra: small sample size; no possibility for separation } \\
\text { of the effects of weight loss and carbohydrate deficit; } \\
\text { no information about approval by the ethics commit- } \\
\text { tee; no intention to treat analysis }\end{array}$ & $1 b-$ \\
\hline Khodabakhshi et al. [23] & $\mathrm{RCT}$ & $\begin{array}{l}\text { Rating according to SIGN } \\
\text { Positive: } 3 \text { points } \\
\text { Uncertain: } 3 \text { points } \\
\text { Negative: } 2 \text { points } \\
\text { Overall quality: acceptable }\end{array}$ & $\begin{array}{l}\text { PRO: study protocol approved by responsible research } \\
\text { institute; power analysis; groups are comparable } \\
\text { Contra: small sample size, especially concerning the } \\
\text { subgroup of neoadjuvant-treated patients; no survival } \\
\text { analysis for the whole study population, only for } \\
\text { subgroup of neoadjuvant-treated patients; unclear if } \\
\text { intention to tread analysis was actually performed, } \\
\text { since only information about patients that completed } \\
\text { the study is given; duration of follow-up for survival } \\
\text { analysis is longer than timeframe from start of patient } \\
\text { enrollment to submission of the article }\end{array}$ & $2 b-$ \\
\hline Cohen et al. $[32,42,56]$ & RCT & $\begin{array}{l}\text { Rating according to SIGN } \\
\text { Positive: } 4 \text { points } \\
\text { Uncertain: } 2 \text { points } \\
\text { Negative: } 3 \text { points } \\
\text { Overall quality: acceptable }\end{array}$ & $\begin{array}{l}\text { PRO: compliance surveilled in arm A with weekly urine } \\
\text { ketone measurement; inclusion of the demographic } \\
\text { characteristics as covariates during analysis; power } \\
\text { analysis; groups are comparable; study approved by } \\
\text { the local institutional review board } \\
\text { Contra: no adjustment for multiple testing; no intention } \\
\text { to treat analysis; high drop-out; possible side effects } \\
\text { are not mentioned }\end{array}$ & $2 b$ \\
\hline Klement et al. [33] & CT & $\begin{array}{l}\text { Rating according to SIGN } \\
\text { Positive: } 3 \text { points } \\
\text { Uncertain: } 1 \text { point } \\
\text { Negative: } 0 \text { points } \\
\text { Overall quality: acceptable }\end{array}$ & $\begin{array}{l}\text { PRO: compliance surveilled in arm A with weekly } \\
\text { beta-hydroxybutyrate blood measurement and patient } \\
\text { questioning; analysis including the most important } \\
\text { factors using linear mixed effects model; groups are } \\
\text { comparable; study approved by the ethics committee } \\
\text { Contra: small sample size, especially in arm A; no } \\
\text { possibility for separation of the effects of ketogenic } \\
\text { diet and amino acid supplementation; low objectively } \\
\text { measured diet adherence using blood beta-hydroxybu- } \\
\text { tyrate levels }(69 \%)\end{array}$ & $3 b$ \\
\hline Ok et al. [34] & $\mathrm{CT}$ & $\begin{array}{l}\text { Rating according to SIGN } \\
\text { Positive: } 3 \text { points } \\
\text { Uncertain: } 0 \text { points } \\
\text { Negative: } 1 \text { point } \\
\text { Overall quality: acceptable }\end{array}$ & $\begin{array}{l}\text { PRO: study protocol approved by responsible institu- } \\
\text { tional review board; groups are comparable } \\
\text { Contra: small sample size; no possibility for separation } \\
\text { of the effects of carbohydrate deficit and smaller but } \\
\text { more frequent servings per day in intervention group; } \\
\text { no power analysis; high drop-out; short follow-up }\end{array}$ & $3 b$ \\
\hline
\end{tabular}

RCT: randomized controlled trial; CT: non-randomized controlled trial; SIGN checklist: Scottish Intercollegiate Guidelines Network Methodology: Checklist 2: Randomized Controlled Trials

An exception is the study of Fine et al. [31], which reported that patients with stable disease or partial remission on PET scan after the diet exhibited significantly higher dietary ketosis than those with progressive disease $(n=4$, $p=0.018$ ).

\section{Feasibility and adherence}

\section{Results from RCTs and CTs}

Out of the included 322 patients, which were included in 
Table 3 Risk of bias in the included single-arm studies and case reports according to the Cochrane risk of bias tool

\begin{tabular}{|c|c|c|c|c|c|c|c|}
\hline Study & RSQ & $\mathrm{AC}$ & BPP & $\mathrm{BOA}$ & IOD & SR & OSB \\
\hline Champ et al. [45] & - & - & - & - & + & + & + \\
\hline Fearon et al. [44] & - & - & - & - & + & + & + \\
\hline Fine et al. [31] & - & - & - & - & + & + & + \\
\hline Jansen and Walach [54] & - & - & - & - & + & + & - \\
\hline Klement and Sweeney [41] & - & - & - & - & + & + & + \\
\hline Martin-McGill et al. [35] & - & - & - & - & - & + & - \\
\hline Martin-McGill et al. [49] & - & - & - & - & + & + & - \\
\hline Rieger et al. [30] & - & - & - & - & + & + & - \\
\hline Schmidt et al. [36] & - & - & - & - & - & + & + \\
\hline Tan-Shalaby et al. [37] & - & - & - & - & - & + & + \\
\hline van der Louw et al. [29] & - & - & - & - & - & + & + \\
\hline Woodhouse et al. [28] & - & - & - & ? & + & + & + \\
\hline Zahra et al. KETOLUNG [38] & - & - & - & - & - & + & + \\
\hline Zahra et al. KETOPAN [38] & - & - & - & - & - & + & + \\
\hline Bozzetti et al. [48] & - & - & - & - & + & + & + \\
\hline Schwartz et al. [39] & - & - & - & - & + & + & + \\
\hline Zuccoli et al. [46] & - & - & - & - & + & + & + \\
\hline Tóth and Clemens [47] & - & - & - & - & + & + & + \\
\hline Bozzetti et al. [20] & - & - & - & - & + & + & + \\
\hline Branca et al. [57] & - & - & - & - & + & + & + \\
\hline Nebeling et al. [40] & - & - & - & - & + & + & + \\
\hline Rossi-Fanelli et al. [43] & - & - & - & - & + & + & + \\
\hline Schroeder et al. [58] & - & - & - & - & + & + & + \\
\hline Artzi et al. [21] & - & - & - & - & + & + & + \\
\hline Iyikesici [26] & - & - & - & - & + & + & + \\
\hline Iyikesici [27] & - & - & - & - & + & + & + \\
\hline Strowd et al. [25] & - & - & - & - & + & + & + \\
\hline Moore [50] & - & - & - & - & + & + & - \\
\hline Elsakka et al. [59] & - & - & - & - & + & + & + \\
\hline Schwalb et al. [55] & - & - & - & - & + & + & - \\
\hline Brünings [60] & - & - & - & - & $?$ & $?$ & $?$ \\
\hline Brünings [61] & - & - & - & - & $?$ & $?$ & $?$ \\
\hline Schütz [62] & - & - & - & - & ? & ? & ? \\
\hline
\end{tabular}

the 5 studies 72 drop-outs occurred (24.7\%). From the 72 drop-outs, 38 (53\%) were part of the intervention group and $34(47 \%)$ of the control group [23, 24, 32-34].

\section{Results from single-arm studies and case reports}

Feasibility and diet adherence was analyzed in 13 studies. In total, 84 out of 139 patients $(60 \%)$ were able to continue the diet for the duration of the intervention $[21,25,28-31$, $35-40]$.

\section{Quality of life}

Cohen et al. used the physical component summary (PCS) and mental component summary (MCS) out of the Short Form (12) Health Survey (SF12) questionnaire to measure the quality of life (QoL) and functioning of the patients. After adjusting for baseline values and chemotherapy score, the PCS score was significantly better in the KD group. There were no significant between-group differences concerning the MCS score [32].

QoL was measured in 4 studies using the EORTC QLQC30 questionnaire [29, 36, 37, 41]. The results were overall inconsistent, but most often reporting stable or decreasing QoL [29, 36, 41].

\section{Changes in body weight}

\section{Results from RCTs and CTs}

All 3 RCTs reported a significant higher weight loss in the KD group than in the control group [23, 24, 42]. Freedland 
Table 4 Risk of bias in the included single-arm studies and case reports rated with the Oxford criteria

\begin{tabular}{|c|c|c|c|c|}
\hline Reference & Study type & $\begin{array}{l}\text { Standardized } \\
\text { rating of risk of } \\
\text { bias }\end{array}$ & Additional comments on methodology & $\begin{array}{l}\text { Evidence } \\
\text { level } \\
\text { (Oxford) }\end{array}$ \\
\hline
\end{tabular}

Champ et al. [45] Retrospective single-arm clinical study -

PRO: study approved by responsible institutional review board, adherence checked with urine and blood ketone bodies measurements

Contra: small sample size, no standardized KD, no possibility for separation of the side effects caused by KD and concurring radio-chemotherapy

Fearon et al. [44]

Fine et al. [31]

Jansen and Walach [54]

Klement and Sweeney [41] Prospective

Case reports
PRO: study approved by local hospital 4 ethical committee, crossover design to minimize confounding by covariates

Contra: small sample size, no wash-out period resulting in possible carryover effects, extremely short duration of intervention

PRO: study approved by responsible committee on clinical investigations, adherence checked with written food-recall records and blood ketone bodies measurements

Contra: small sample size, no standardized $\mathrm{KD}$, no possibility for separation of the effects caused by KD and weight loss

PRO:

Contra: small sample size, number of observations for the majority of the variables reported insufficient to perform a reliable statistical analysis; no standardized KD, no information about an approval by the responsible ethics committee; no information about the occurrence of side effects; potential conflict of interest: the first author is a shareholder of the company, that patients were specifically informed about as a source for ketogenic food

PRO: study approved by institutional ethics review board, adherence checked with food diaries written by the patients and monitoring of ketone levels in urine and blood

Contra: very small sample size, no standardized $\mathrm{KD}$, no possibility for separation of the effects caused by $\mathrm{KD}$ and radio(chemo)therapy 
Table 4 (continued)

\begin{tabular}{lll}
\hline Reference & Study type & $\begin{array}{l}\text { Standardized } \\
\text { rating of risk of } \\
\text { bias }\end{array}$
\end{tabular} \begin{tabular}{l} 
Additional comments on methodology \\
$\begin{array}{l}\text { Evidence } \\
\text { level } \\
\text { (Oxford) }\end{array}$ \\
\hline
\end{tabular}

Martin-McGill et al. [35] Randomized, mixed methods, feasibility study

Martin-McGill et al. [49]

Rieger et al. [30]

Schmidt et al. [36]

Tan-Shalaby et al. [37]

van der Louw et al. [29]
Prospective single-arm pilot study

Prospective single-arm pilot study

Prospective, single-arm pilot study

Single-arm prospective feasibility trial _

Prospective single-arm feasibility study -
PRO: study approved by local research 4 ethics committee, adherence checked with food diaries written by the patients and monitoring of ketone levels in urine and blood; randomized

Contra: small sample size, potential conflict of interest: the first author received a $\mathrm{PhD}$ studentship of the company, that provided the mediumchain triglyceride nutritional products used in Arm A; two co-authors received salary costs from the same company

PRO: study approved by local

Research, Development and Innovation committee; adherence checked with food diaries written by the patients and monitoring of ketone levels in urine

Contra: very small sample size, potential conflict of interest: the first author received a $\mathrm{PhD}$ studentship from a company, that produces KD foods and supplements

PRO: study approved by local institutional review boards of the participating hospitals; adherence checked with nutritional questionnaires and monitoring of ketone levels in urine

Contra: relatively small sample size, potential conflict of interest: one of the co-authors is the founder of a company, that produces KD foods and supplements and provided the nutritional packages used in the study; data not stratified by center

PRO: study approved by local ethics committee; adherence checked with patient documenting food intake and monitoring of ketone levels in urine

Contra: small sample size, no standardization of KD despite carbohydrate intake

PRO: study approved by local Independent Review Board

Contra: small sample size, no standardized KD; no possibility for separation of the effects caused by KD and weight loss

PRO: study approved by local medical ethical committee; adherence checked with monitoring of the ketone body levels in the blood

Contra: small sample size, no possibility for separation of the effects caused by KD and radio-chemotherapy 
Table 4 (continued)

\begin{tabular}{|c|c|c|c|c|}
\hline Reference & Study type & $\begin{array}{l}\text { Standardized } \\
\text { rating of risk of } \\
\text { bias }\end{array}$ & Additional comments on methodology & $\begin{array}{l}\text { Evidence } \\
\text { level } \\
\text { (Oxford) }\end{array}$ \\
\hline Woodhouse et al. [28] & $\begin{array}{l}\text { Retrospective single-arm feasibility } \\
\text { study }\end{array}$ & - & $\begin{array}{l}\text { PRO: study approved by local insti- } \\
\text { tutional review board; adherence } \\
\text { checked with monitoring of the } \\
\text { ketone body levels in the blood } \\
\text { Contra: small sample size, no pos- } \\
\text { sibility for separation of the effects } \\
\text { caused by KD and radio-chemo- } \\
\text { therapy; retrospective study that } \\
\text { only includes patients who achieved } \\
\text { ketosis }\end{array}$ & 4 \\
\hline Zahra et al. KETOLUNG [38] & $\begin{array}{l}\text { Prospective single-arm phase } 1 \text { clinical } \\
\text { trial }\end{array}$ & - & $\begin{array}{l}\text { PRO: study approved by local insti- } \\
\text { tutional review board; adherence } \\
\text { checked with food diaries written by } \\
\text { the patients and monitoring of the } \\
\text { ketone body levels in the blood } \\
\text { Contra: small sample size, no pos- } \\
\text { sibility for separation of the effects } \\
\text { caused by KD and radio-chemother- } \\
\text { apy }\end{array}$ & 4 \\
\hline Zahra et al. KETOPAN [38] & $\begin{array}{l}\text { Prospective single-arm phase } 1 \text { clinical } \\
\text { trial }\end{array}$ & - & $\begin{array}{l}\text { PRO: study approved by local insti- } \\
\text { tutional review board; adherence } \\
\text { checked with food diaries written by } \\
\text { the patients and monitoring of the } \\
\text { ketone body levels in the blood } \\
\text { Contra: small sample size, no pos- } \\
\text { sibility for separation of the effects } \\
\text { caused by KD and radio-chemother- } \\
\text { apy }\end{array}$ & 4 \\
\hline Bozzetti et al. [48] & Single case report & - & $\begin{array}{l}\text { PRO: adherence secured, due to paren- } \\
\text { teral feeding } \\
\text { CONTRA: only a single patient } \\
\text { analyzed }\end{array}$ & 4 \\
\hline Schwartz et al. [39] & Case Report & - & $\begin{array}{l}\text { PRO: study approved by local insti- } \\
\text { tutional review board; adherence } \\
\text { checked with monitoring of the } \\
\text { ketone body levels in the blood } \\
\text { CONTRA: extremely small sample } \\
\text { size }\end{array}$ & 4 \\
\hline Zuccoli et al. [46] & Case Report & - & $\begin{array}{l}\text { PRO: } \\
\text { CONTRA: only a single patient } \\
\text { analyzed; no possibility for separa- } \\
\text { tion of the effects caused by KD and } \\
\text { radio-chemotherapy; no systematic } \\
\text { assessment of adverse effects }\end{array}$ & 4 \\
\hline Tóth and Clemens [47] & Case report & - & $\begin{array}{l}\text { PRO: adherence checked with monitor- } \\
\text { ing of ketone levels in urine } \\
\text { CONTRA: only a single patient ana- } \\
\text { lyzed; no possibility for separation of } \\
\text { the effects caused by KD and radio- } \\
\text { therapy; no systematic assessment of } \\
\text { adverse effects; no standardized KD }\end{array}$ & 4 \\
\hline Bozzetti et al. [20] & Single-arm prospective Study & - & $\begin{array}{l}\text { PRO: power analysis } \\
\text { Contra: small sample size; due to die- } \\
\text { tary intervention of only 3-h results } \\
\text { can hardly be translated to the effects } \\
\text { of a long-term dietary intervention }\end{array}$ & 4 \\
\hline
\end{tabular}


Table 4 (continued)

\begin{tabular}{|c|c|c|c|c|}
\hline Reference & Study type & $\begin{array}{l}\text { Standardized } \\
\text { rating of risk of } \\
\text { bias }\end{array}$ & Additional comments on methodology & $\begin{array}{l}\text { Evidence } \\
\text { level } \\
\text { (Oxford) }\end{array}$ \\
\hline Branca et al. [57] & Single case report & - & $\begin{array}{l}\text { PRO: } \\
\text { Contra: only a single patient analyzed; } \\
\text { no assessment of adverse effects }\end{array}$ & 4 \\
\hline Nebeling et al. [40] & Case reports & - & $\begin{array}{l}\text { PRO: study approved by local } \\
\text { institutional review board; adher- } \\
\text { ence checked with food diaries and } \\
\text { monitoring of the ketone body levels } \\
\text { in blood and urine } \\
\text { Contra: small sample size; no system- } \\
\text { atic assessment of adverse effects; } \\
\text { no possibility for separation of the } \\
\text { effects caused by KD and radio- } \\
\text { chemotherapy }\end{array}$ & 4 \\
\hline Rossi-Fanelli et al. [43] & 3-Arm prospective Study & - & $\begin{array}{l}\text { PRO: adherence secured, due to paren- } \\
\text { teral feeding } \\
\text { Contra: no assessment of adverse } \\
\text { effects }\end{array}$ & $3 b$ \\
\hline Schroeder et al. [58] & Prospective quantitative study & - & $\begin{array}{l}\text { PRO: study approved by local research } \\
\text { ethics committee; prospective study } \\
\text { Contra: no assessment of adverse } \\
\text { effects; no standardized diet; due } \\
\text { to dietary intervention lasting only } \\
4 \text { days at most, results can hardly be } \\
\text { translated to the effects of a long- } \\
\text { term dietary intervention }\end{array}$ & 4 \\
\hline Artzi et al. [21] & Prospective, 2 arm pilot study & - & $\begin{array}{l}\text { PRO: study approved by local insti- } \\
\text { tutional review board; adherence } \\
\text { checked with monitoring of the } \\
\text { ketone body levels in the urine } \\
\text { Contra: no assessment of adverse } \\
\text { effects; small sample size; control } \\
\text { group added retrospectively }\end{array}$ & 4 \\
\hline Iyikesici [26] & Single-arm retrospective study & - & $\begin{array}{l}\text { PRO: due to the retrospective nature no } \\
\text { institutional review board approval } \\
\text { required } \\
\text { Contra: no standardized diet; no pos- } \\
\text { sibility for separation of the effects } \\
\text { caused by the KD and the additional } \\
\text { treatments, including: polychemo- } \\
\text { therapy and hyperthermia }\end{array}$ & 4 \\
\hline Iyikesici [27] & Single-arm retrospective study & - & $\begin{array}{l}\text { PRO: due to the retrospective nature no } \\
\text { institutional review board approval } \\
\text { required } \\
\text { Contra: no standardized diet; no pos- } \\
\text { sibility for separation of the effects } \\
\text { caused by the KD and the additional } \\
\text { treatments, including: polychemo- } \\
\text { therapy, hyperbaric oxygen therapy } \\
\text { and hyperthermia }\end{array}$ & 4 \\
\hline Strowd et al. [25] & Single-arm study & - & $\begin{array}{l}\text { PRO: study approved by institutional } \\
\text { review board; adherence checked } \\
\text { with monitoring of the ketone body } \\
\text { levels in blood and urine } \\
\text { Contra: no structured assessment of } \\
\text { adverse effects; small sample size }\end{array}$ & 4 \\
\hline
\end{tabular}


Table 4 (continued)

\begin{tabular}{|c|c|c|c|c|}
\hline Reference & Study type & $\begin{array}{l}\text { Standardized } \\
\text { rating of risk of } \\
\text { bias }\end{array}$ & Additional comments on methodology & $\begin{array}{l}\text { Evidence } \\
\text { level } \\
\text { (Oxford) }\end{array}$ \\
\hline Moore [50] & Single case report & - & $\begin{array}{l}\text { PRO: } \\
\text { Contra: no structured assessment of } \\
\text { adverse effects; no possibility for } \\
\text { separation of the effects caused by } \\
\text { KD and chemotherapy }\end{array}$ & 4 \\
\hline Elsakka et al. [59] & Single case report & - & $\begin{array}{l}\text { PRO: study approved by institutional } \\
\text { review board } \\
\text { Contra: no structured assessment of } \\
\text { adverse effects; no possibility for } \\
\text { separation of the effects caused by } \\
\text { KD and other treatments including } \\
\text { surgery, radiation, chemotherapy and } \\
\text { other novel treatments }\end{array}$ & 4 \\
\hline Schwalb et al. [55] & Case reports & - & $\begin{array}{l}\text { PRO: } \\
\text { Contra: small sample size; no struc- } \\
\text { tured assessment of adverse effects; } \\
\text { no possibility for separation of the } \\
\text { effects caused by the KD and the } \\
\text { additional novel treatments, including } \\
\text { high dose vitamin D, colostrum and } \\
\text { multiple food supplements; two of } \\
\text { the authors own companies, which } \\
\text { produced most of the food supple- } \\
\text { ments used in this trial }\end{array}$ & 4 \\
\hline Brünings [60] & Case reports & - & $\begin{array}{l}\text { PRO: } \\
\text { Contra: historic study, from a cur- } \\
\text { rent standpoint outdated and often } \\
\text { subjective methods used to assess the } \\
\text { effects of the diet }\end{array}$ & 4 \\
\hline Brünings [61] & Case reports & - & $\begin{array}{l}\text { PRO: } \\
\text { Contra: historic study, from a cur- } \\
\text { rent standpoint outdated and often } \\
\text { subjective methods used to assess the } \\
\text { effects of the diet }\end{array}$ & 4 \\
\hline Schulte and Schütz [62] & Case reports & - & $\begin{array}{l}\text { PRO: } \\
\text { Contra: historic study, from a cur- } \\
\text { rent standpoint outdated and often } \\
\text { subjective methods used to assess the } \\
\text { effects of the diet }\end{array}$ & 4 \\
\hline
\end{tabular}

$K D$ ketogenic diet

et al. [24] found a weight loss of $12.1 \mathrm{~kg}$ in the intervention group, compared to a weight loss of $0.5 \mathrm{~kg}$ in the control group $(p<0.001)$ during the 6 months of the diet. The study of Khodabakhshi et al. [23] reported a significantly larger weight loss in the intervention group than in the control group over the course of a 3 month diet with $6.3 \mathrm{~kg}$ compared to $1.3 \mathrm{~kg}$, respectively $(p<0.001)$. Over the same 3-month duration Cohen et al. [42] detected a weight loss of $6.1 \mathrm{~kg}$ in the intervention group and $3 \mathrm{~kg}$ in the control group $(p<0.05)$.

In one of the controlled trials by Ok et al. [34], there were no significant differences in the reduction of body weight between both groups $(p=0.475)$. In the other trial by Klement et al. [33], only regression coefficients for the changes in body weight were provided. Here, a significantly higher reduction of body weight was reported for the subgroup of breast cancer patients $(p=0.00014)$ and rectal cancer patients $(p=0.01)$. However, in the subgroup of HNC (head and neck cancer) patients the regression coefficient for "Time $\times$ KD" implied a significant positive effect of the KD on the body weight of the patients $(p=0.008)$ [33].

\section{Results from single-arm studies and case reports}

Changes in bodyweight were analyzed in 15 studies. A statistical analysis to check for significance was performed 


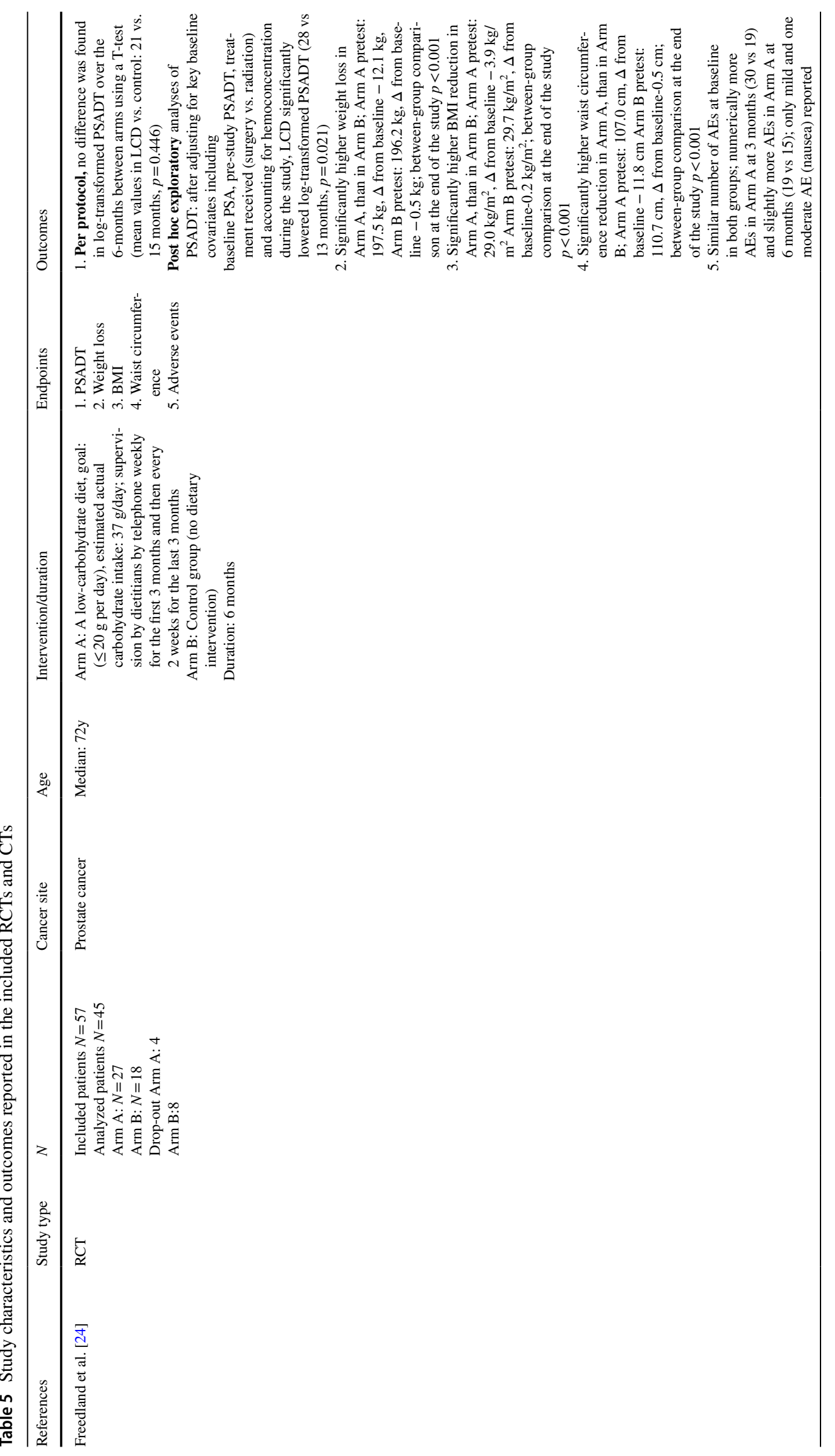




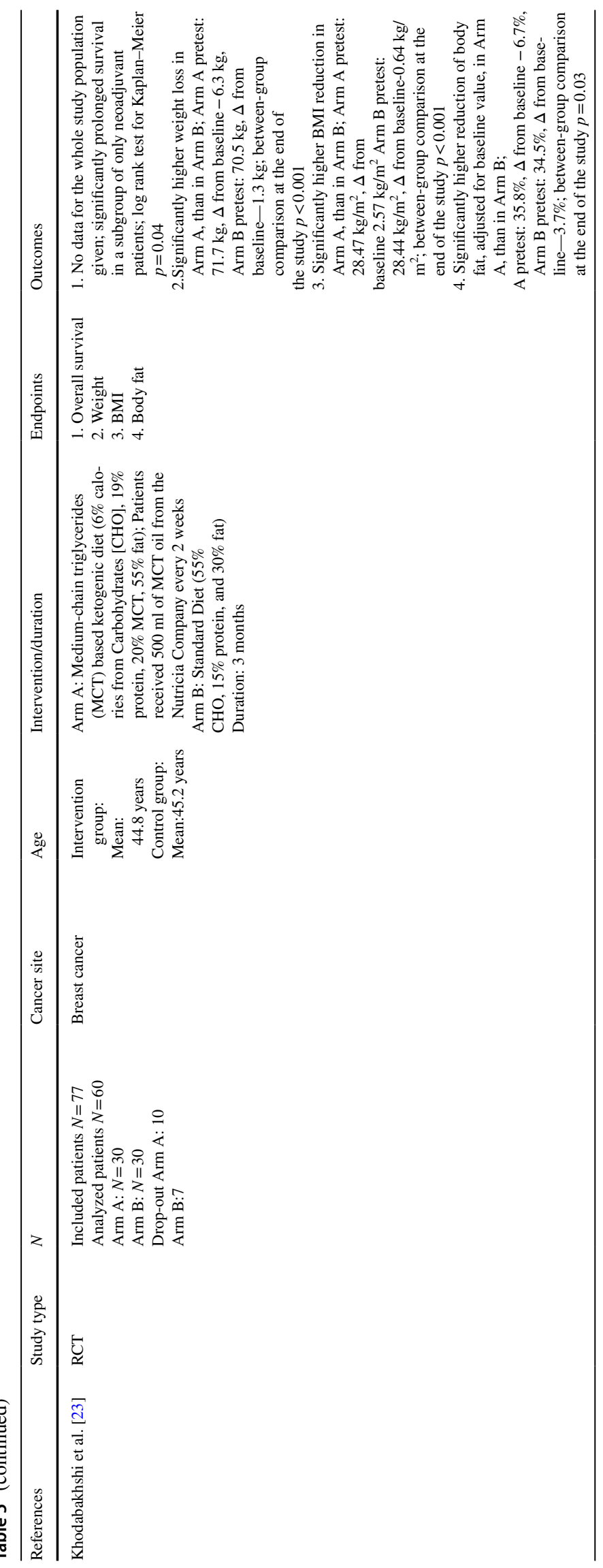




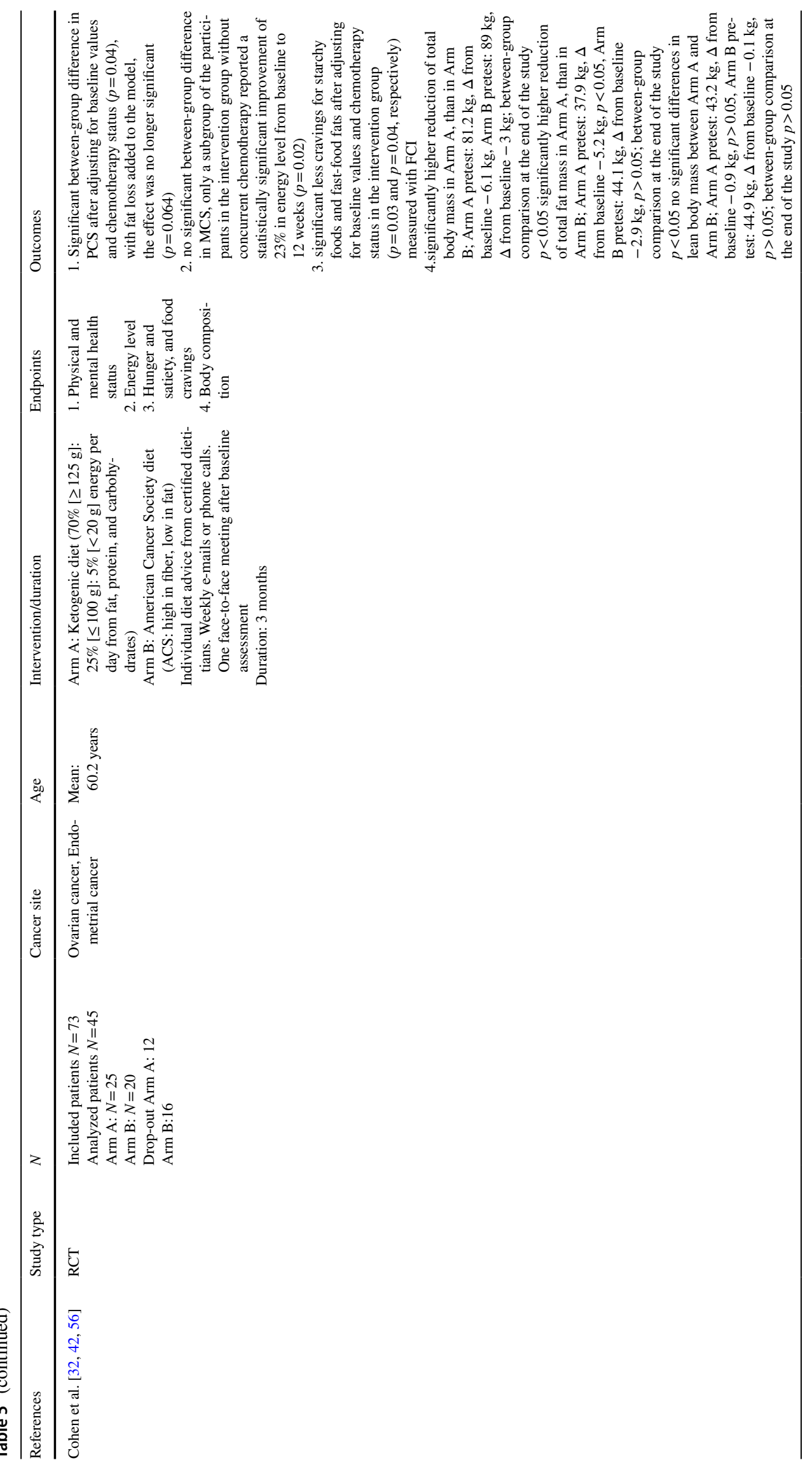




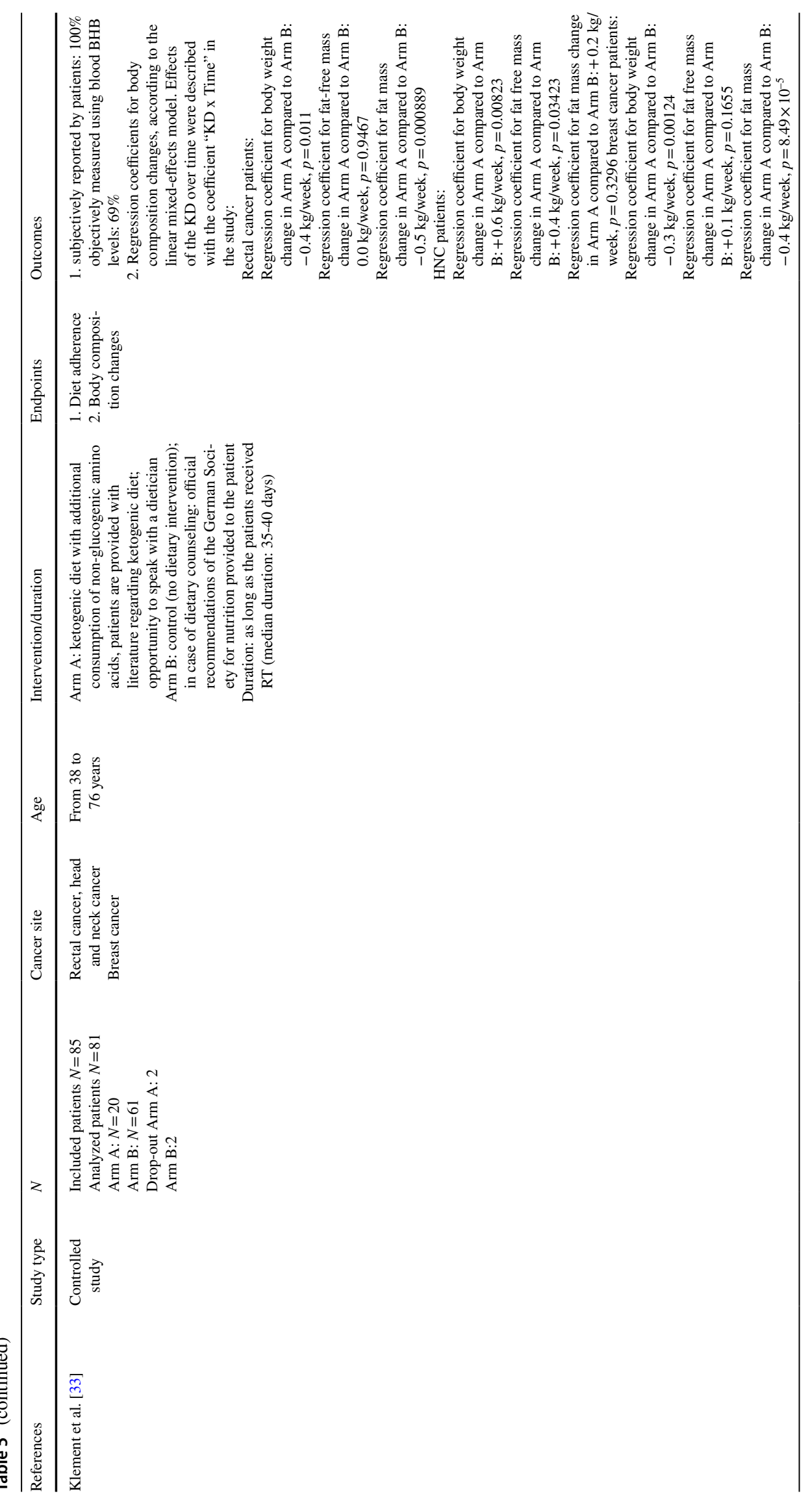




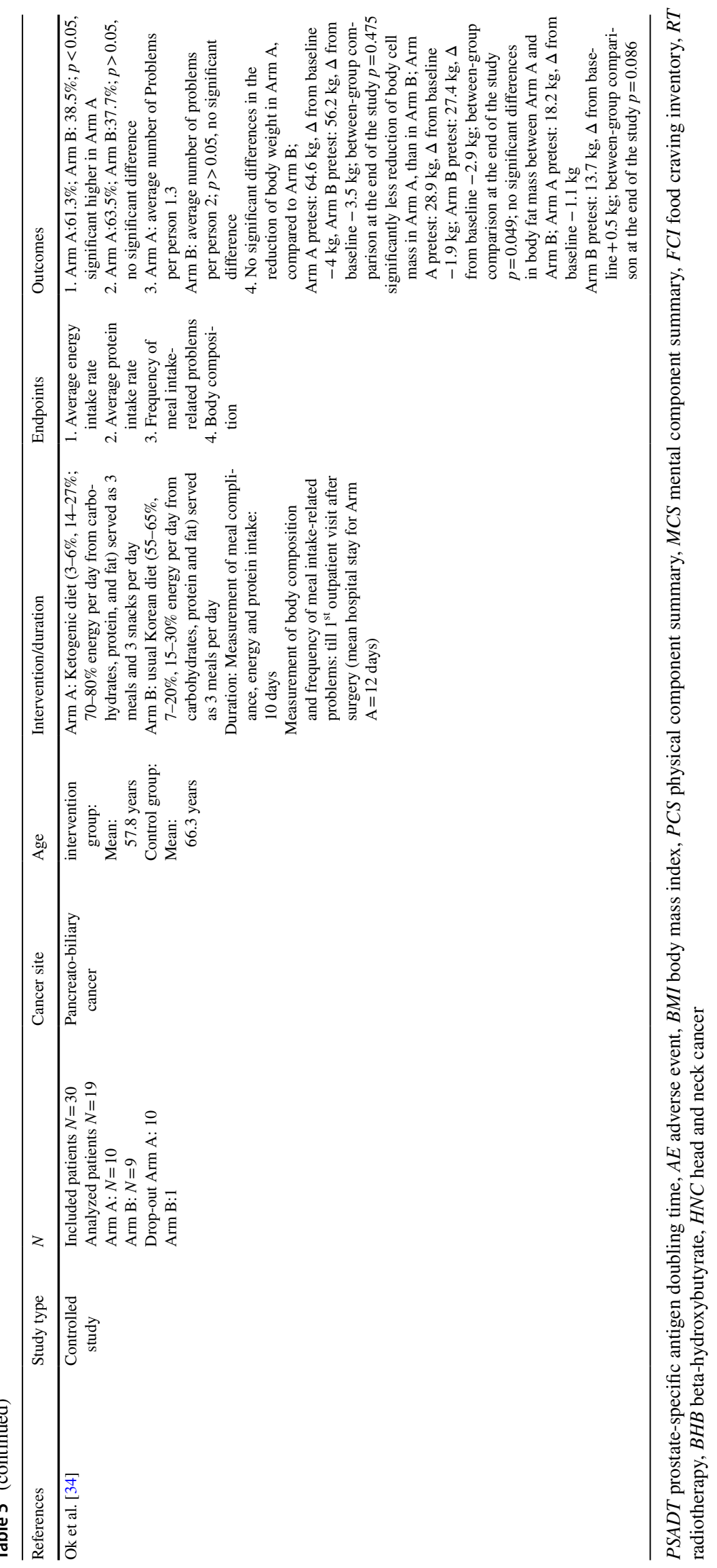

望 Springer 
in 8 studies, of which 4 found a significant reduction in bodyweight $[30,36,37,41]$. Three of these studies found a non-significant decrease in body weight $[25,31,43]$ and only Fearon et al. [44] showed a significant increase in body weight.

Out of the remaining seven studies, where no statistical analysis was performed, weight loss during the diet occurred in six studies [38, 39, 45-47], while only one study showed an increase in body weight [48].

One study assessed the change in BMI and reported a median decline of $1.04 \mathrm{~kg} / \mathrm{m}^{2}$, without checking for significance [28].

\section{Changes in body composition}

\section{Results from RCTs and CTs}

Changes in body composition were analyzed in one RCT and both CTs. The RCT by Cohen et al. found a significant higher reduction of total fat mass in the $\mathrm{KD}$ group $(-5.2 \mathrm{~kg})$ than in the control group $(-2.9 \mathrm{~kg})$, while no significant differences concerning the lean body mass occurred [42].

Klement et al. provided primarily the regression coefficients for the fat mass (FM) and fat-free mass (FFM). In the subgroup of rectal cancer patients, a significantly greater loss of FM occurred in the KD group, without significant differences in FFM. A comparable result was reported in the subgroup of breast cancer patients, who experienced a significant reduction in FM, while the FFM reduction was not significant. However, the $50 \mathrm{kHz}$ phase angle, an indicator for changes in cell mass, also significantly declined in the KD group. In the subgroup of HNC patients, the regression coefficients implied a significant increase in FFM in patients receiving a KD [33].

Ok et al. found a significantly lower reduction in body cell mass in the KD group $(-1.9 \mathrm{~kg})$ than in the control group $(-2.9 \mathrm{~kg})$, while no significant differences in body fat mass occurred [34].

\section{Results from single-arm studies and case reports}

Two studies analyzed changes in body composition [35, 41]. One study showed a significant FM reduction, without significant reduction in FFM [41], whereas the other study showed no significant effects on body composition [35].

\section{Adverse events}

\section{Results from RCTs and CTs}

Only one RCT [24] and one CT [34] monitored adverse events and only the CT by Ok et al. used a validated tool [34]. In the RCT by Freedland et al. [24], only mild AEs and one moderate $\mathrm{AE}$ (nausea) were reported. The number of AEs was similar at baseline but increased drastically in the KD group (30 vs 19 reported AEs) at 3 months. At 6 months, the number of AEs had subsided back to baseline in the KD group and was again close to the number in the control group at the same time.

Ok et al. [34] assessed the number of meal intake-related problems and postoperative complications. No significant differences between both groups in either of the two categories occurred.

\section{Results from single-arm studies and case reports}

Adverse events were monitored in 19 studies. A validated tool was used in 11 of the 19 studies [26-29, 31, 35, 37, 38, $45,46]$. Since many studies combined KD with standard of care (SoC) chemotherapy and/or radiation therapy, it was often not possible to determine the cause of the reported AEs. Most of the AEs were mild to moderate. The most common AEs include: fatigue [31, 45], constipation [29, 31], diarrhea [29, 35] as well as nausea and vomiting [29, 35]. Further reported AEs were: deep venous thrombosis, asymptomatic hypoglycemia, nephrolithiasis, leg cramps, dyspepsia, dry mouth, hyperuricemia, hyperlipidemia, pedal edema, anemia, neutropenia and febrile neutropenia, thrombocytopenia, halitosis, pruritus, hypoglycemia, hyperkalemia, hypokalemia, hypomagnesemia, flu-like symptoms, low carnitine, hallucinations, allergic reaction, wound infection, headaches and neuropathy [26-31, 35-39, 45-50].

Even though most AEs were mild to moderate, there were also DLTs (dose-limiting toxicity) like CTCAE (NCI Common Terminology Criteria for Adverse Events) grade 3 dehydration, grade 4 hyperuricemia [38] and a case of grade 5 neutropenia, resulting in the death of the patient [26].

\section{Discussion}

\section{Summary of main results}

The basic idea of using a KD to prohibit cancer growth relies on the Warburg hypothesis and successful animal and cell culture studies. However, clinical evidence demonstrating a beneficent effect on survival and anti-tumor efficiency is still lacking.

The RCT conducted by Freedland et al. [24] failed to detect a significant anti-tumor effect in per-protocol analysis and an effect was only visible in a strongly adjusted exploratory analysis. Only Khodabakhshi et al. [23] found a significantly longer OS of the neoadjuvant treated subgroup of breast cancer patients. But said data are only presented as a Kaplan-Meier plot, without any further information, despite a $p$ value of 0.04 and the claim of a higher survival rate in 


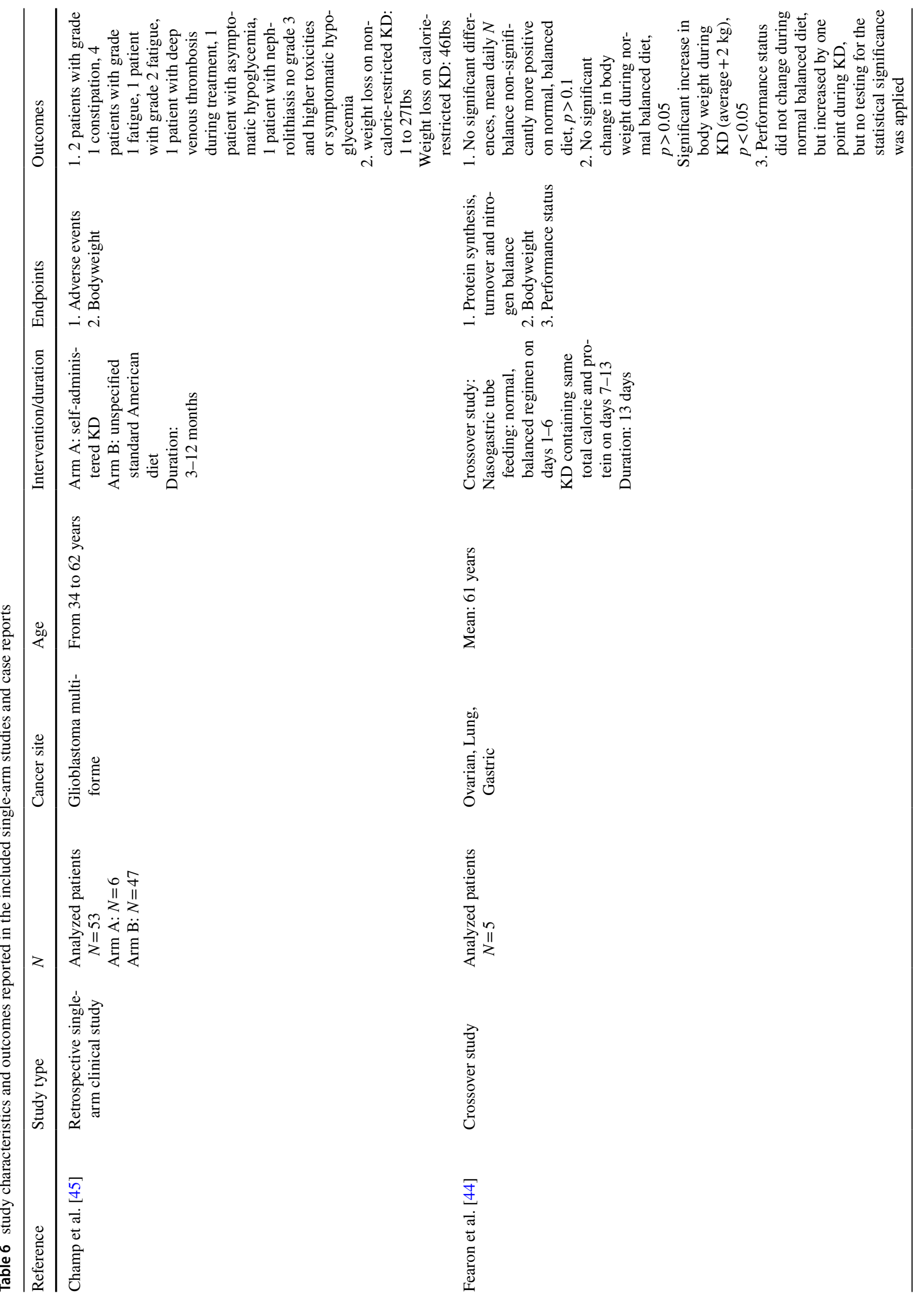




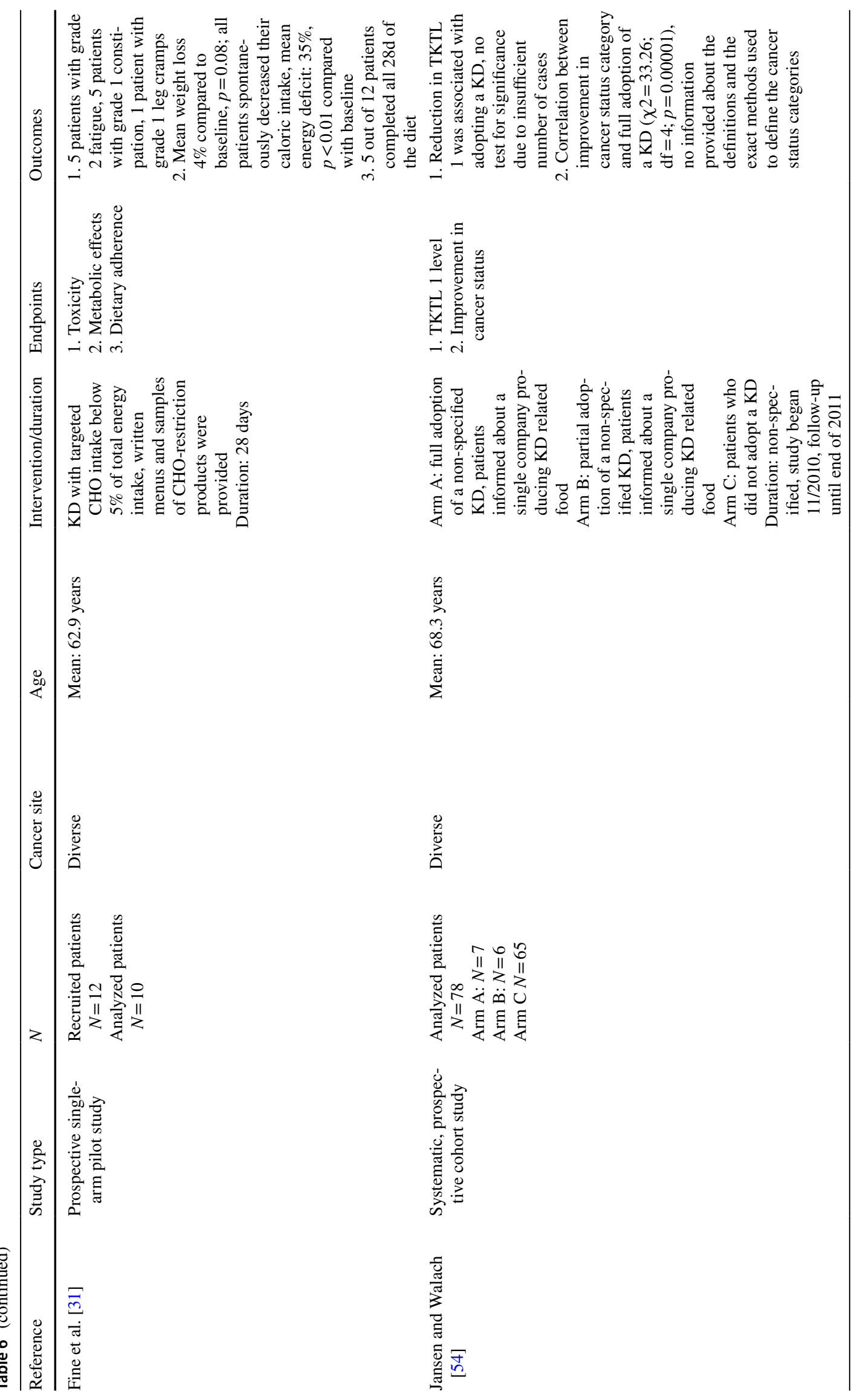




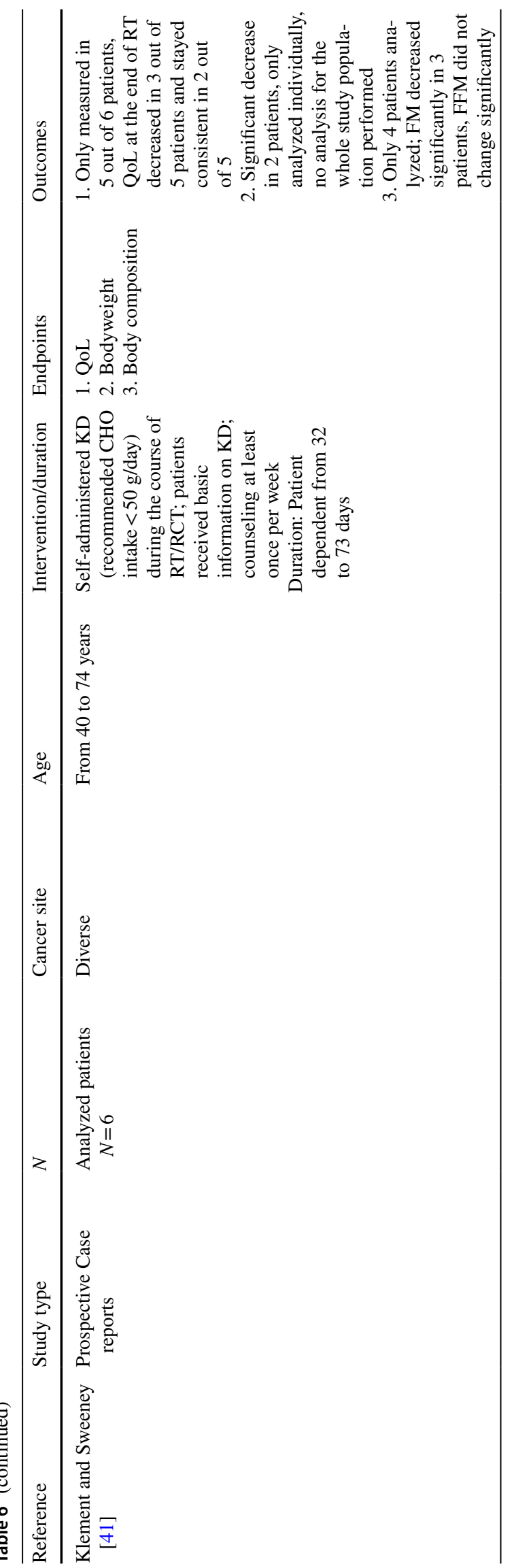




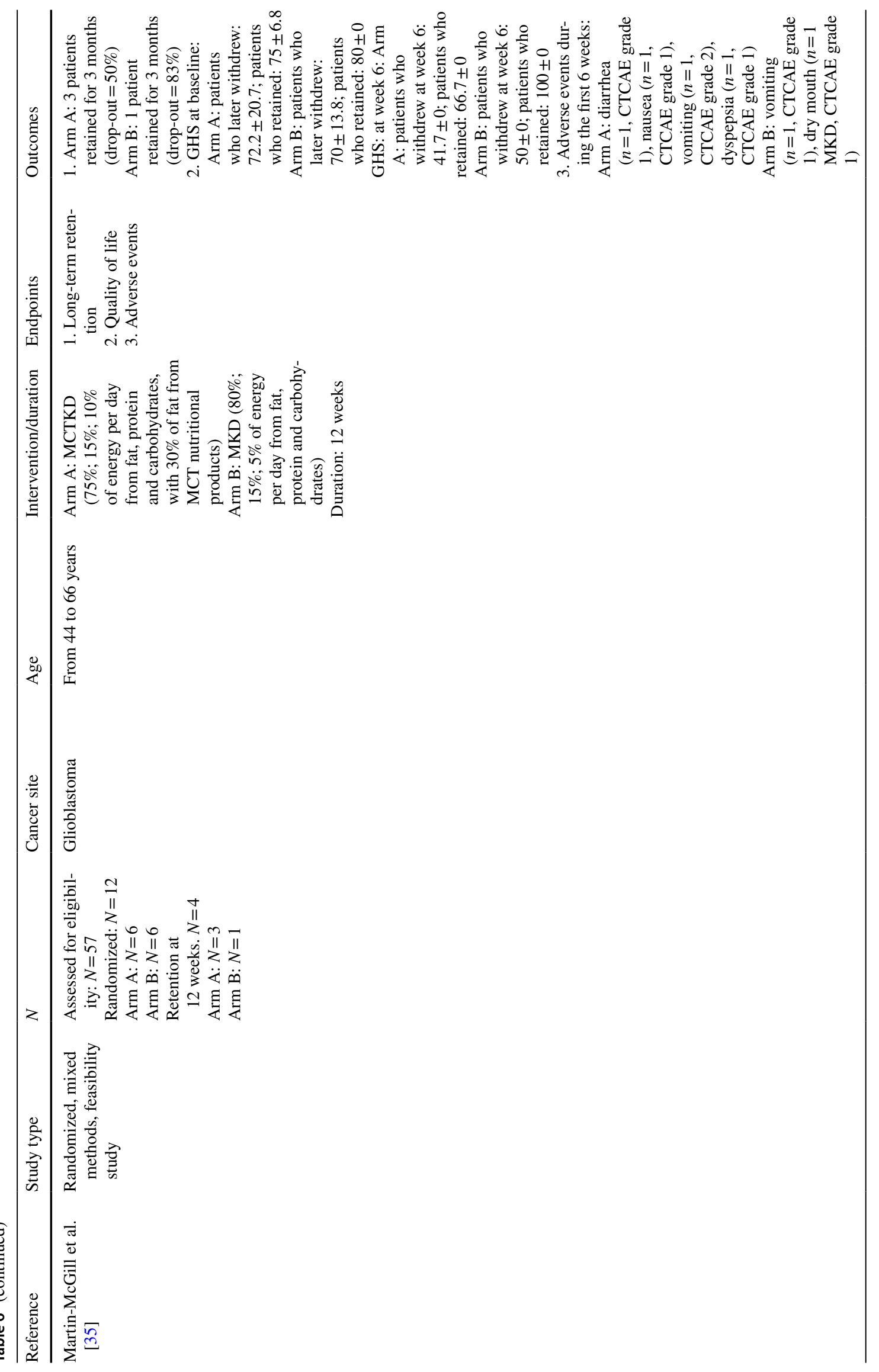




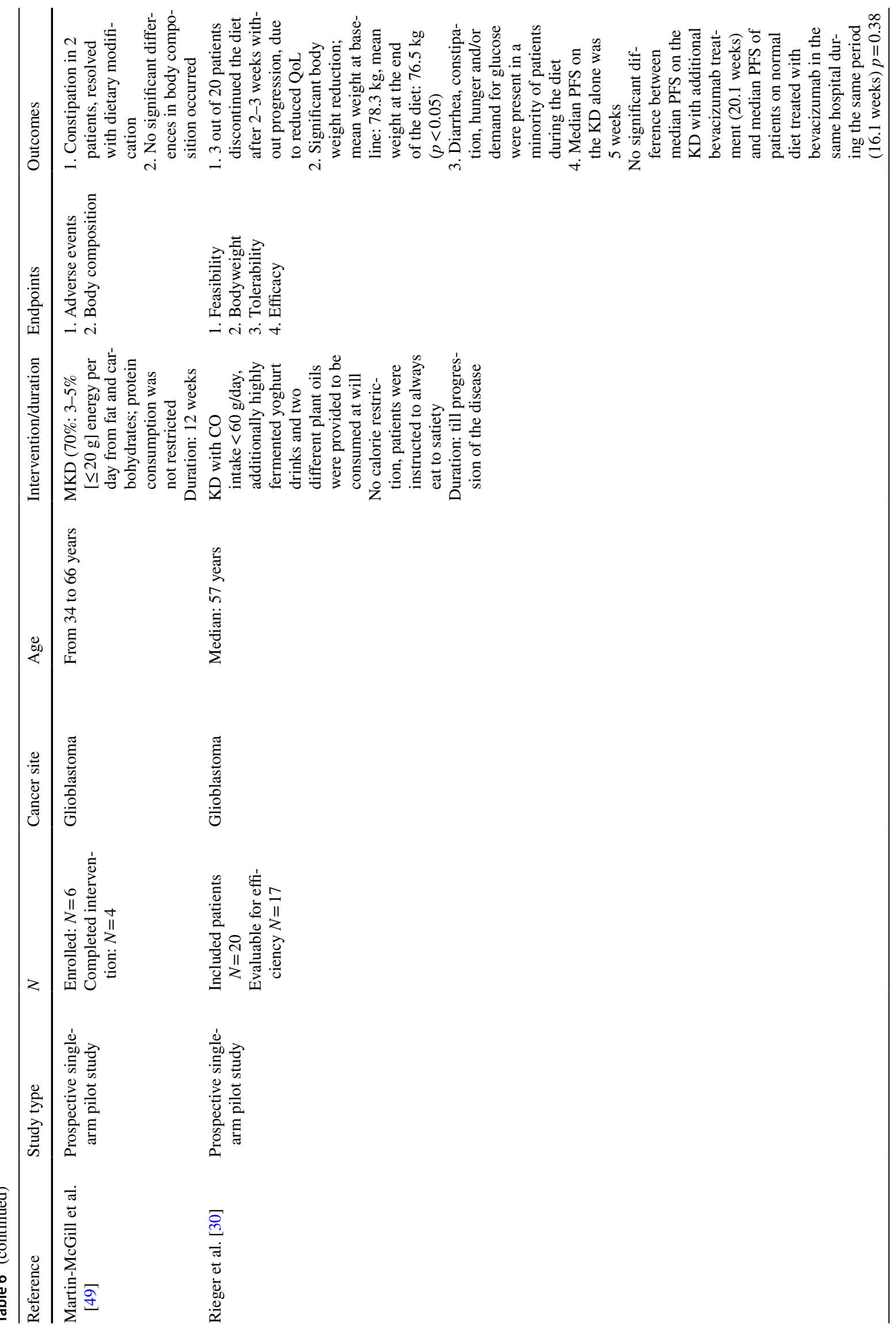




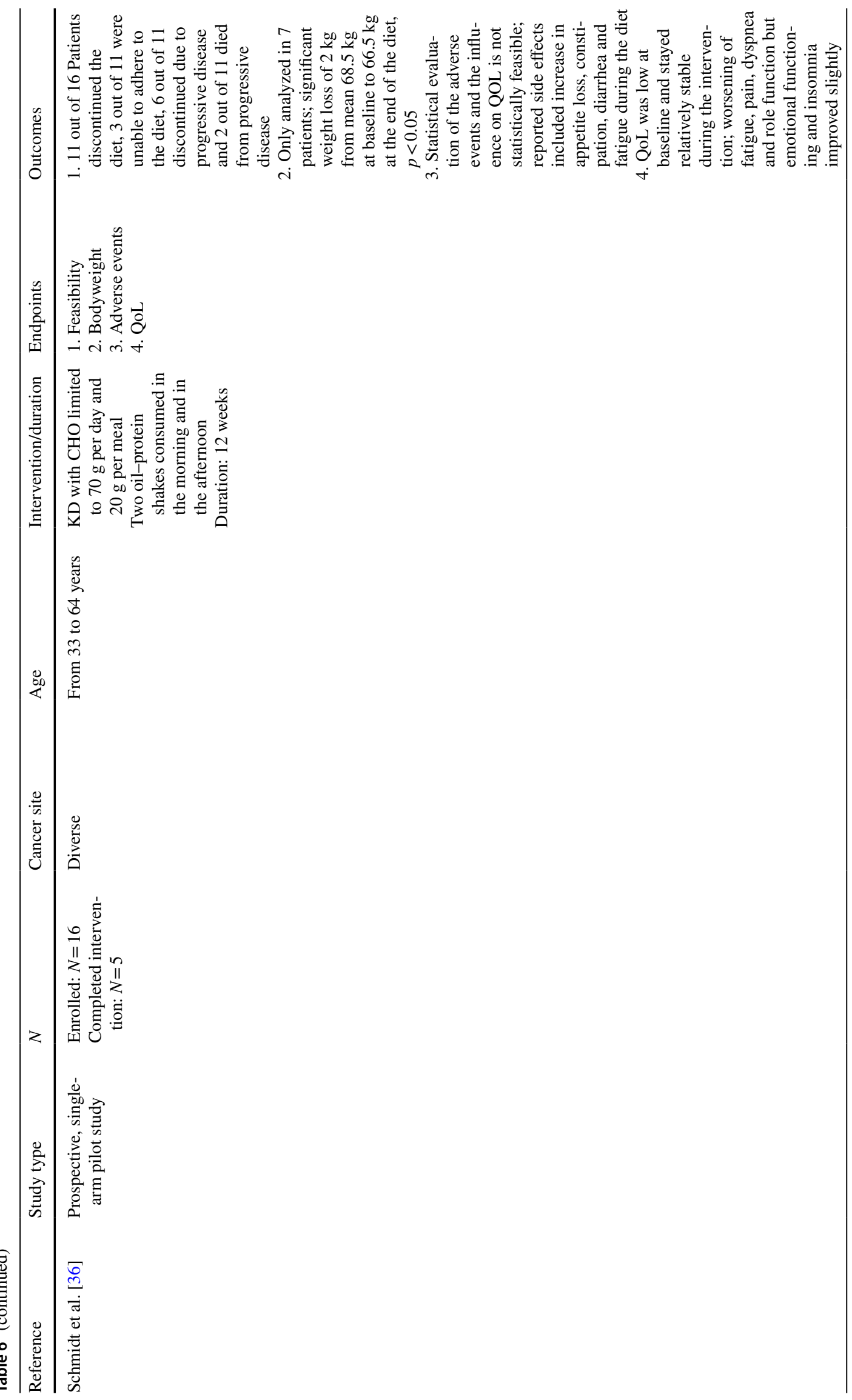




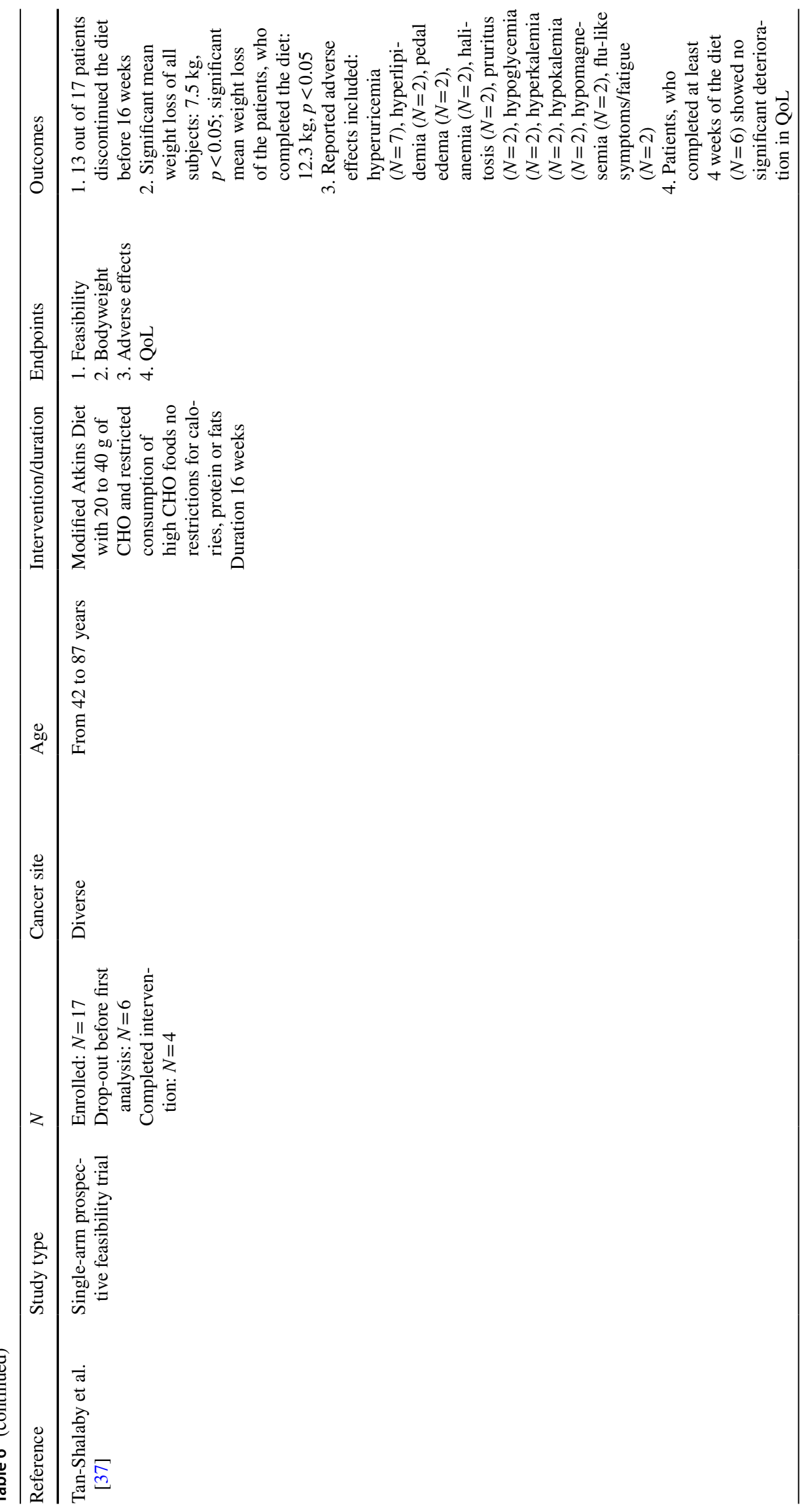




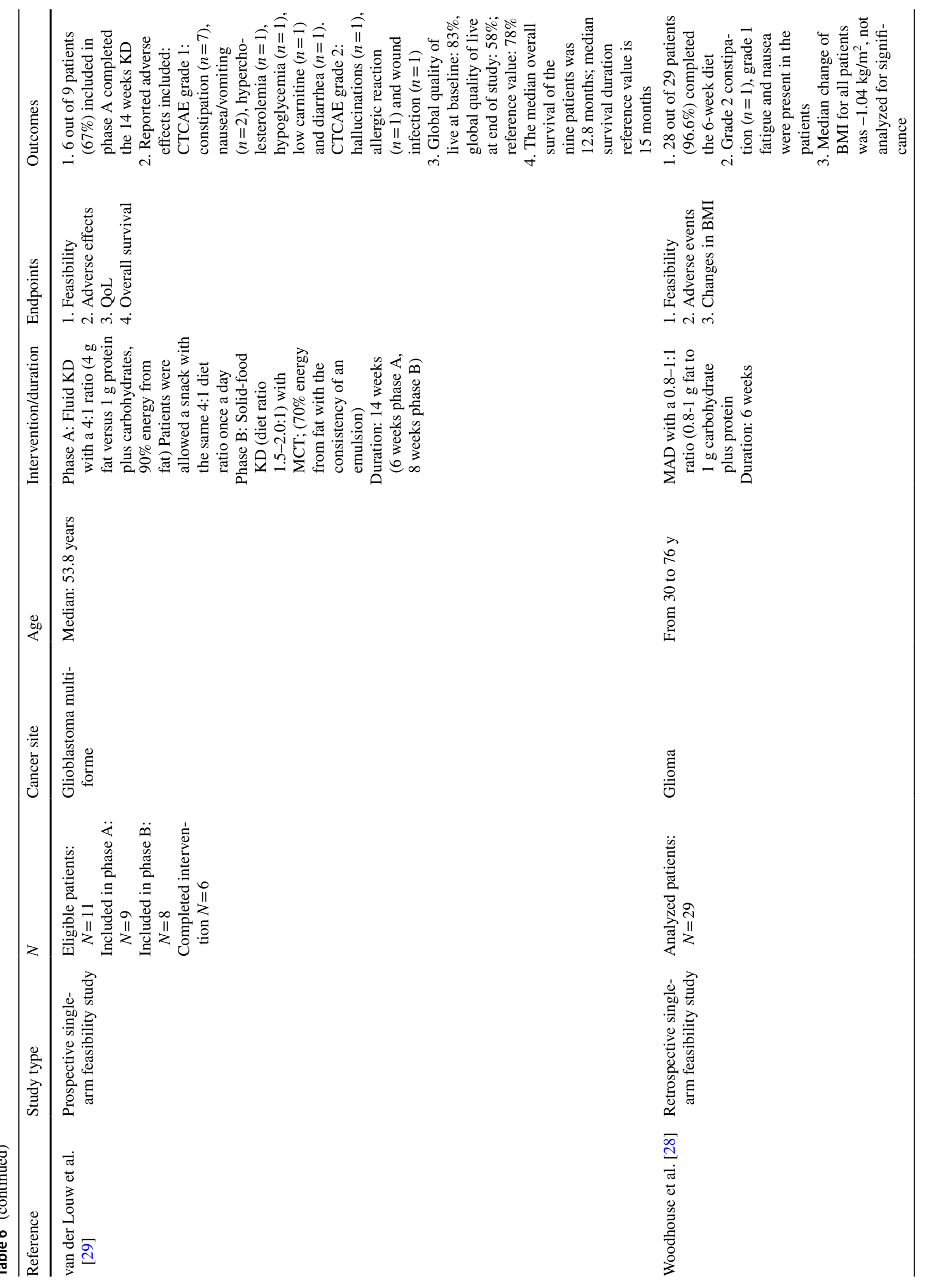




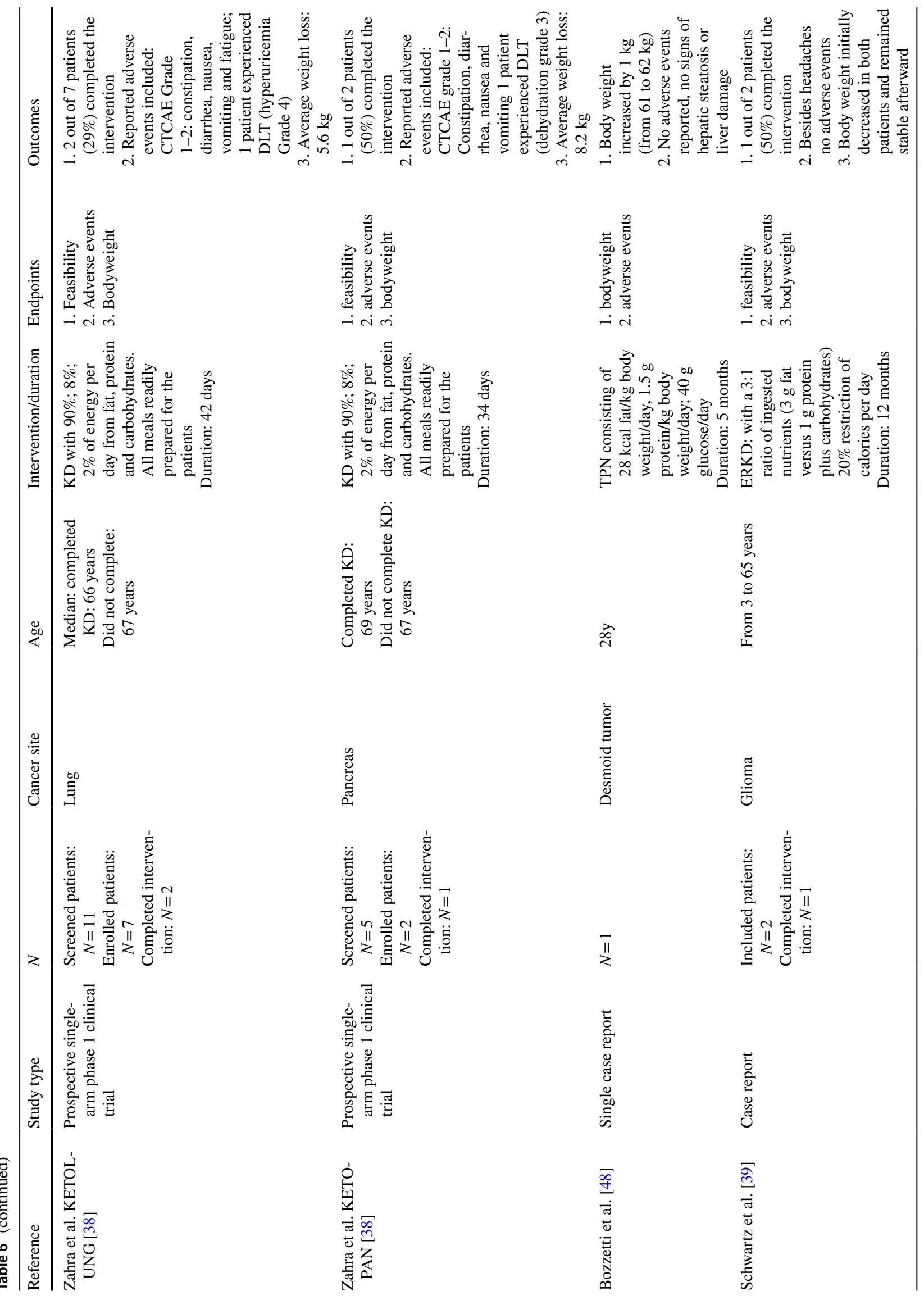




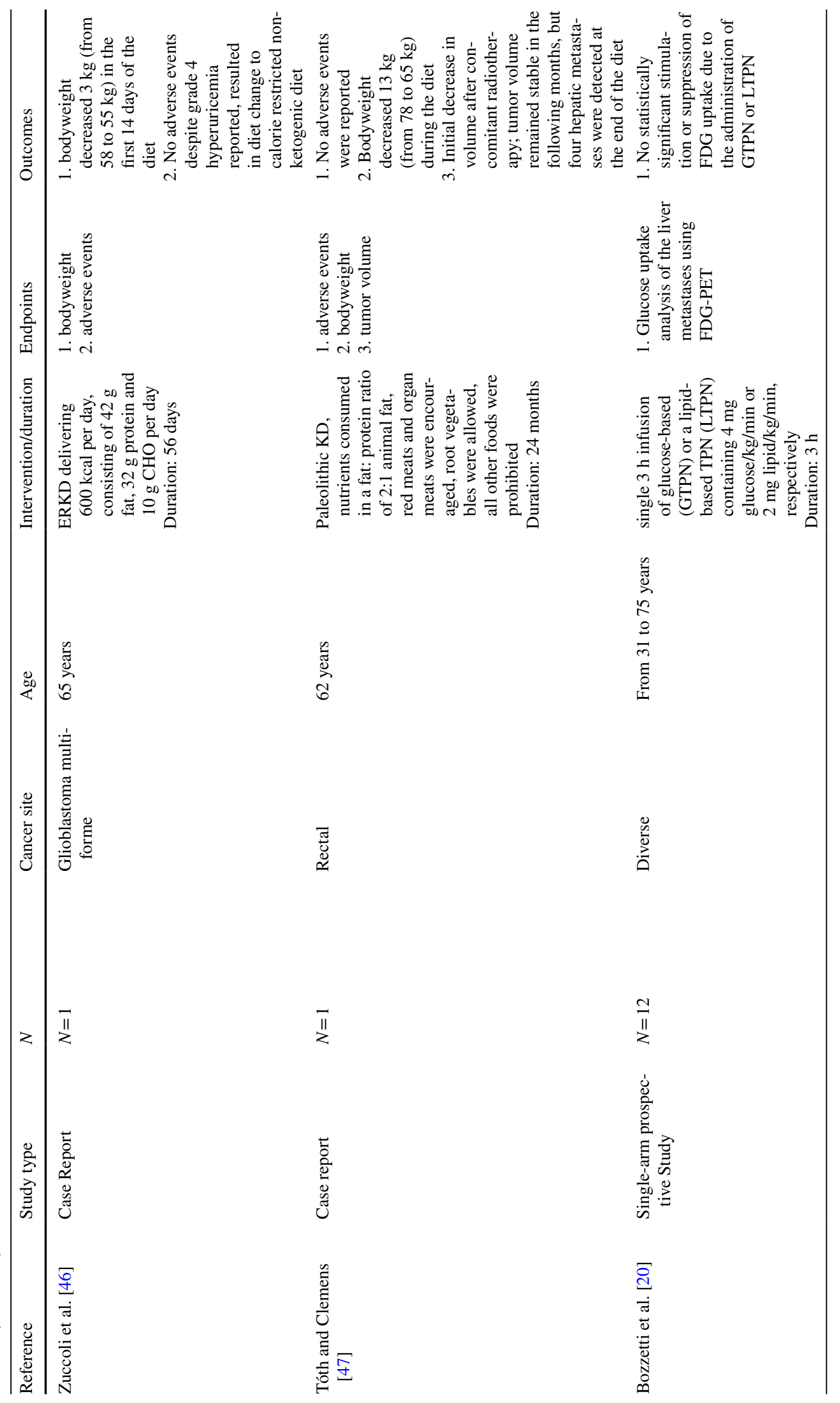




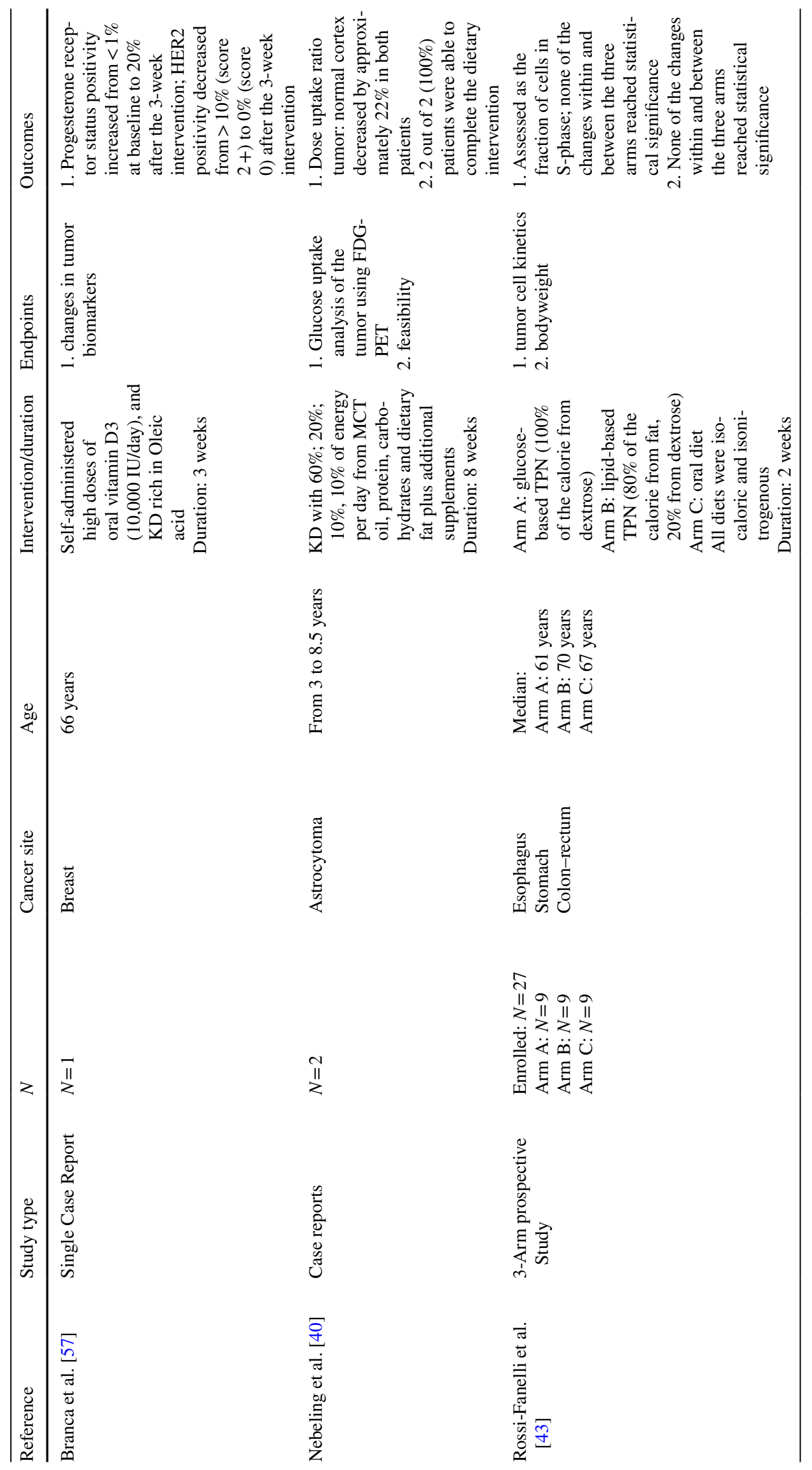




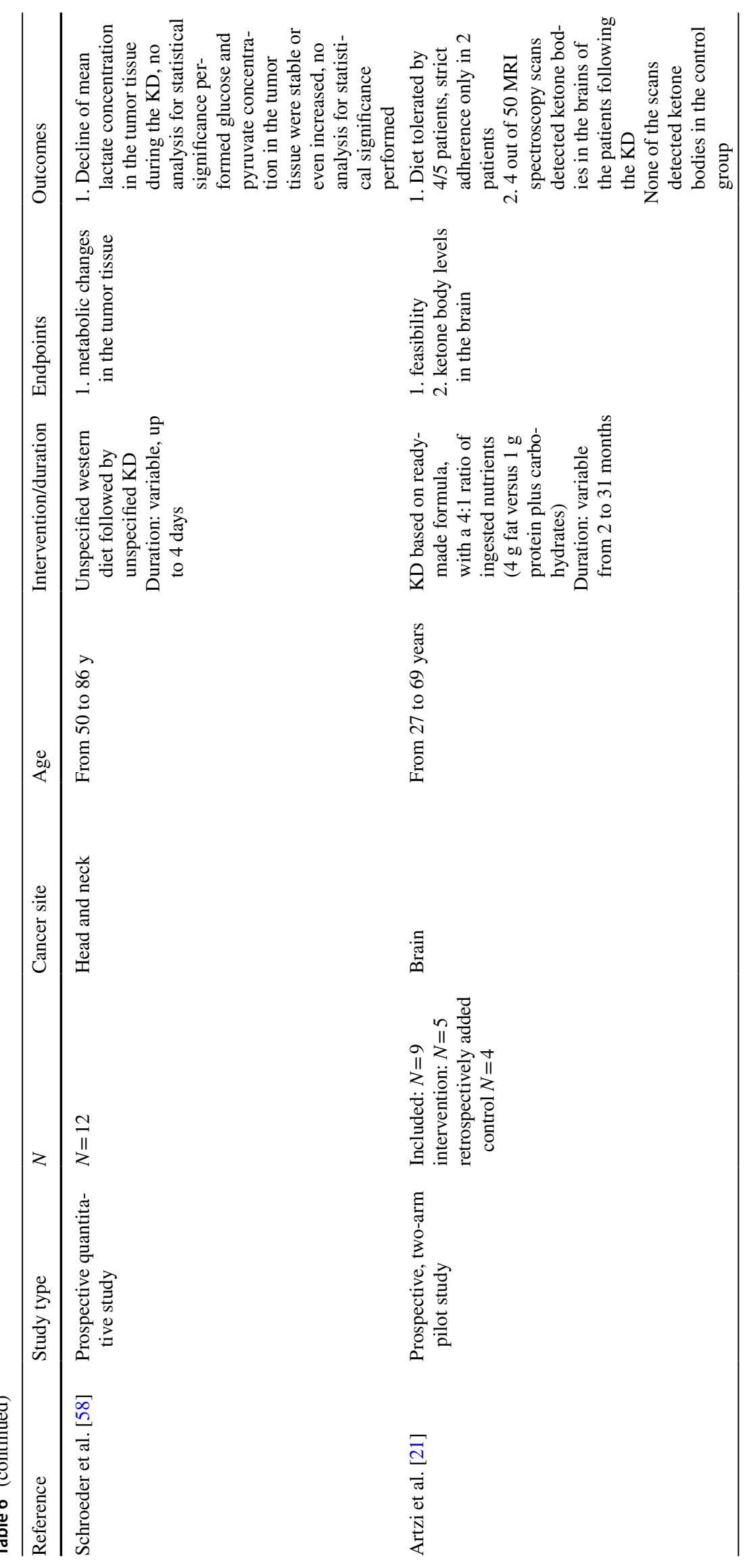




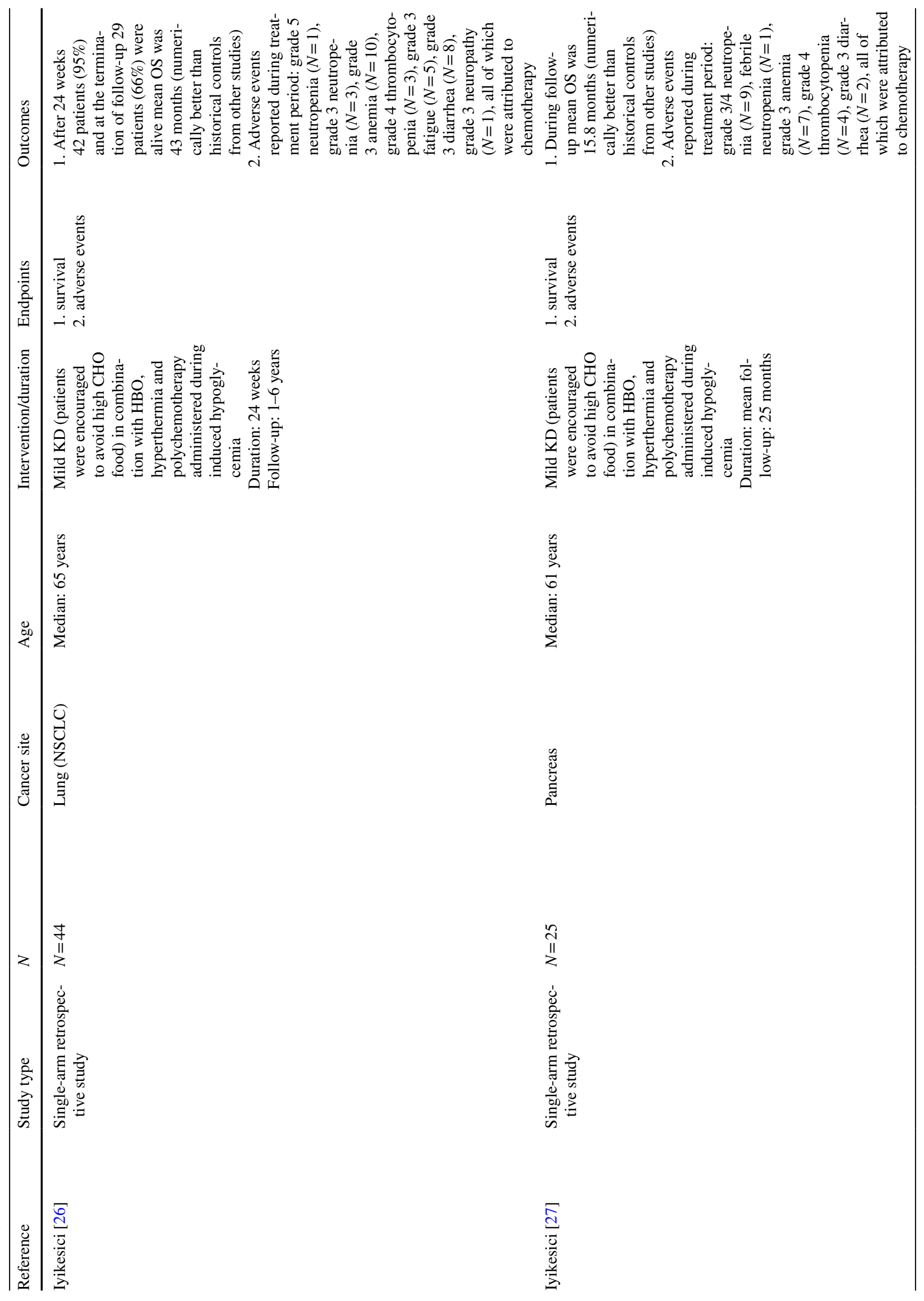




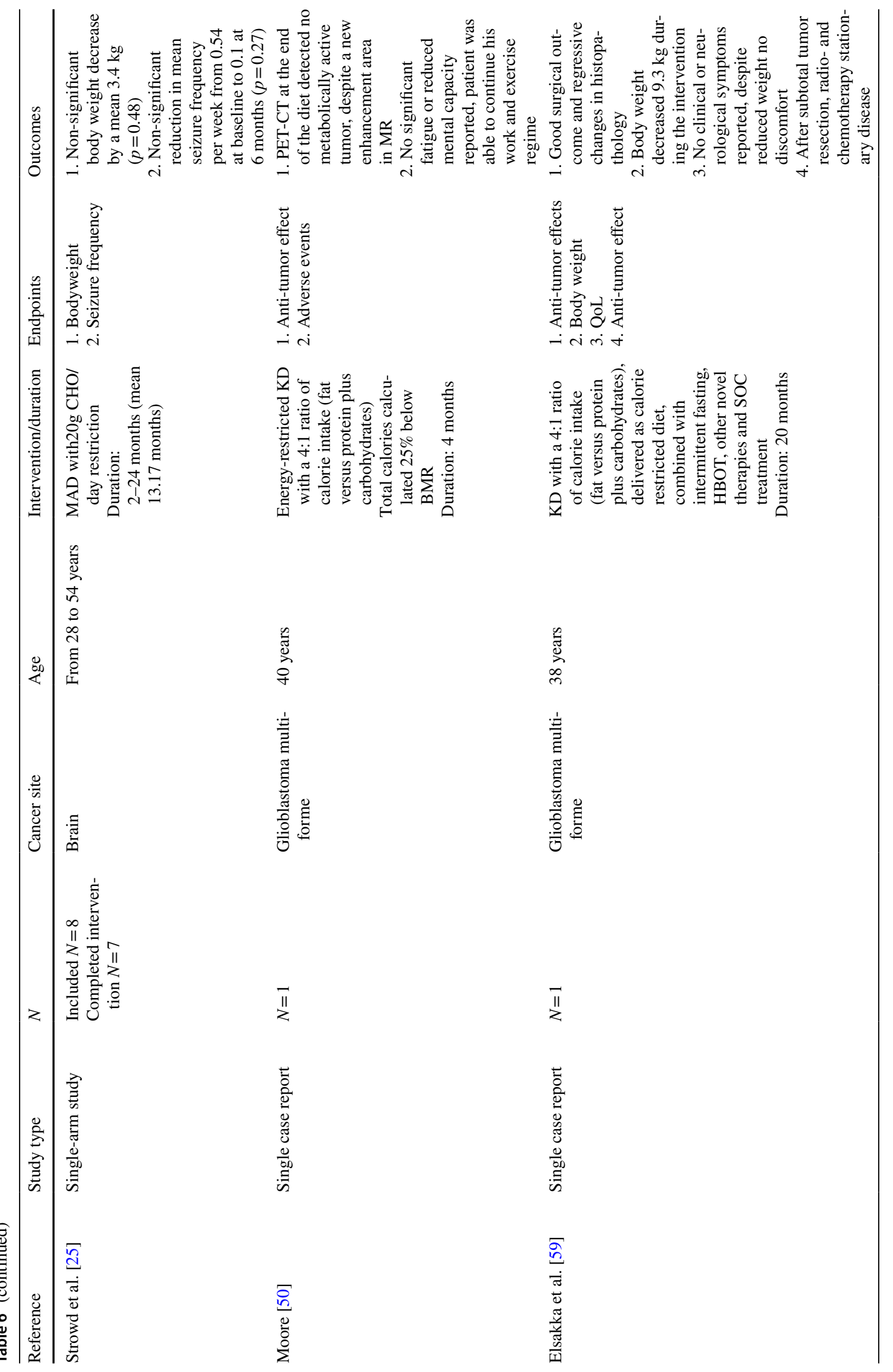




$$
\text { min }
$$


the KD group. It is also noteworthy that the follow-up time in this study's Kaplan-Meier plot appears to be 26 months. However, the recruitment started in 07/2017 and stopped in 10/2018. The finished article was received by the publishing journal in $02 / 2019$. This is just 4 months after the last patient was recruited. The resulting follow-up is 19 months at most for the first patients recruited. Furthermore, the KD was only administered for 3 months. These inconsistencies raise serious concerns regarding the presented data. Additionally, no data were provided for the subgroup of metastatic patients in this publication. Even though the data from these patients were not published as an original publication, they are reported in a systematic review by Klement et al. [51]. Here, the patients in the KD group had a numerically shorter OS $(p=0.078)$.

The studies in this review showed an overall low adherence to the $\mathrm{KD}$, but the drop-out rates varied greatly between studies. Important reasons for low adherence were: limitations in monitoring and delivery [39], patients finding the meals unpalatable [38] and problems trying to integrate the diet into family life [36].

QoL was only assessed in a few studies. The RCT by Cohen et al. [32] was only able to show a significant improvement in perceived physical functioning after adjusting for several variables and without adjusting for weight loss, which attenuated the effect. No beneficial effects on mental functioning were found in this trial. This is in line with other studies, which also failed to show a QoL benefit of the KD [29, 36].

Almost all controlled and non-controlled studies showed a weight loss during the $\mathrm{KD}$, which was often significant, if statistical analysis was performed [23, 24, 42]. This is rather concerning, since malnourishment, sarcopenia and cancer cachexia have been shown to negatively impact clinical outcomes and greatly reduce QoL $[52,53]$. For patients with an increased risk of cancer cachexia, a KD can therefore be detrimental and the idea of implementing a KD in these patients should raise serious safety concerns. Nevertheless, studies analyzing body composition revealed that the loss of fat mass appears to be more pronounced than the loss in fat-free mass [41, 42].

The studies in this review showed a variety of adverse events related to a KD. The most frequent were fatigue [31, 45], constipation [29, 31], diarrhea [29, 35] as well as nausea and vomiting $[29,35]$. Despite the fact that most of these were only mild to moderate several serious AEs like grade 3 dehydration and grade 4 hyperuricemia [38] and a case of grade 5 neutropenia occurred [26]. Especially problematic is, that many studies did not measure AEs and the ones that did, often attributed those that happened entirely to the SoC anti-cancer treatments [26]. Thus, the AEs of a KD seem to be underreported.
Finally, it should be noted that definite conclusions are still difficult to ascertain from the available data, due to a high level of bias in most studies, a small number of patients with high level of adherence and the lack of a control group and randomization, further increasing especially allocation, and performance bias. It should also be noted that in several studies the authors had a potential conflict of interest, due to financial and non-financial support or owning shares from companies producing products used in a $\operatorname{KD}[30,35,49$, 54, 55].

Furthermore, the studies are highly heterogenous, in many cases not limited to one cancer type and often use the KD complementary to other therapies, limiting the possibility to assess whether effects and AEs were caused by the diet or other simultaneous interventions-this also impairs the possibility to pool the results to perform a meta-analysis.

\section{Limitations of this work}

Some limitations of this systematic review must be mentioned. For once, due to the heterogeneity of the included RCTs no meta-analysis could be conducted, and no moderators of the effects caused by a KD could be determined. Furthermore, only studies published in English or German were included in this review.

\section{Conclusion}

Even though a variety of studies have been conducted in the past on KDs for cancer patients, evidence for increased survival, anti-tumor efficacy and a reduction of side effects is lacking, even in the most recent controlled trials. More robust and consistent clinical evidence from larger patient groups with comparable methodology, thorough dietary protocols and an assessment of side effects using validated tools are necessary, before a KD can be recommended to most cancer patients. Currently possible side effects including weight loss as well as patient co-morbidities must be carefully weighed when considering applying a KD to cancer patients. To form a final judgment about the efficiency of a $\mathrm{KD}$ in Oncology, a randomized controlled trial with a welldesigned control group and sufficient power to also detect evidence for absence of anti-tumor effects is necessary.

Supplementary Information The online version contains supplementary material available at https://doi.org/10.1007/s10238-021-00710-2.

Authors' contributions MR and JH contributed to development of the protocol. MR and JD collected data and performed analysis. MR and JD performed data interpretation. JH critically revised the article and approved the final version submitted for publication. 
Funding Open Access funding enabled and organized by Projekt DEAL.. The work of JD was funded in parts (search of the literature, title-abstract screening) by the German Guideline "S3 Leitlinie Komplementärmedizin in der Behandlung von onkologischen PatientInnen (Registernummer 032-055OL)" funded by the German Cancer Aid (Fördernummer 11583) within the German Guideline Program in Oncology.

Availability of data and materials The datasets generated during and/or analyzed during the current study are available from the corresponding author on reasonable request.

\section{Declarations}

Conflict of interest The authors declare no conflicts of interest.

Ethics approval Not applicable.

Consent to participate Not applicable.

Consent for publication All authors consent to the publication of this work.

Open Access This article is licensed under a Creative Commons Attribution 4.0 International License, which permits use, sharing, adaptation, distribution and reproduction in any medium or format, as long as you give appropriate credit to the original author(s) and the source, provide a link to the Creative Commons licence, and indicate if changes were made. The images or other third party material in this article are included in the article's Creative Commons licence, unless indicated otherwise in a credit line to the material. If material is not included in the article's Creative Commons licence and your intended use is not permitted by statutory regulation or exceeds the permitted use, you will need to obtain permission directly from the copyright holder. To view a copy of this licence, visit http://creativecommons.org/licenses/by/4.0/.

\section{References}

1. Hickson M, Child J, Collinson A. Future dietitian 2025: informing the development of a workforce strategy for dietetics. J Hum Nutr Diet. 2018;31(1):23-32. https://doi.org/10.1111/jhn.12509.

2. Maschke J, Kruk U, Kastrati K, et al. Nutritional care of cancer patients: a survey on patients' needs and medical care in reality. Int J Clin Oncol. 2017;22(1):200-6. https://doi.org/10.1007/ s10147-016-1025-6.

3. Martin-McGill KJ, Bresnahan R, Levy RG, Cooper PN. Ketogenic diets for drug-resistant epilepsy. Cochrane Database Syst Rev. 2020;6(6):CD001903. https://doi.org/10.1002/14651858.CD001 903.pub5.

4. Warburg O. On the origin of cancer cells. Science. 1956;123(3191):309-14. https://doi.org/10.1126/science.123. 3191.309.

5. Hanahan D, Weinberg RA. Hallmarks of cancer: the next generation. Cell. 2011;144(5):646-74. https://doi.org/10.1016/j.cell. 2011.02.013.

6. Bettum IJ, Gorad SS, Barkovskaya A, et al. Metabolic reprogramming supports the invasive phenotype in malignant melanoma. Cancer Lett. 2015;366(1):71-83. https://doi.org/10.1016/j.canlet. 2015.06.006

7. Allen BG, Bhatia SK, Anderson CM, et al. Ketogenic diets as an adjuvant cancer therapy: history and potential mechanism. Redox Biol. 2014;2:963-70. https://doi.org/10.1016/j.redox.2014.08.002.
8. Hübner J, Marienfeld S, Abbenhardt C, Ulrich CM, Löser C. How useful are diets against cancer? Dtsch Med Wochenschr. 2012;137(47):2417-22. https://doi.org/10.1055/s-0032-1327276.

9. Huebner J, Marienfeld S, Abbenhardt C, et al. Counseling patients on cancer diets: a review of the literature and recommendations for clinical practice. Anticancer Res. 2014;34(1):39-48.

10. Poorshiri B, Barzegar M, Tahmasebi S, Shiva S, Raeisi S, Ebadi Z. The efficacy comparison of classic ketogenic diet and modified Atkins diet in children with refractory epilepsy: a clinical trial. Acta Neurol Belg. 2019. https://doi.org/10.1007/ s13760-019-01225-0.

11. Klement RJ, Champ CE, Otto C, Kämmerer U. Anti-tumor effects of ketogenic diets in mice: a meta-analysis. PLoS ONE. 2016;11(5):e0155050. https://doi.org/10.1371/journal.pone.01550 50 .

12. Khodadadi S, Sobhani N, Mirshekar S, et al. Tumor cells growth and survival time with the ketogenic diet in animal models: a systematic review. Int J Prev Med. 2017;8:35. https://doi.org/10. 4103/2008-7802.207035.

13. Sperry J, Condro MC, Guo L, et al. Glioblastoma utilizes fatty acids and ketone bodies for growth allowing progression during ketogenic diet therapy. iScience. 2020;23(9):101453. https://doi. org/10.1016/j.isci.2020.101453.

14. Kallinowski F, Vaupel P, Runkel S, et al. Glucose uptake, lactate release, ketone body turnover, metabolic micromilieu, and $\mathrm{pH}$ distributions in human breast cancer xenografts in nude rats. Cancer Res. 1988;48(24 Pt 1):7264-72.

15. Bonuccelli G, Tsirigos A, Whitaker-Menezes D, et al. Ketones and lactate "fuel" tumor growth and metastasis: evidence that epithelial cancer cells use oxidative mitochondrial metabolism. Cell Cycle. 2010;9(17):3506-14. https://doi.org/10.4161/cc.9.17. 12731.

16. Martinez-Outschoorn UE, Prisco M, Ertel A, et al. Ketones and lactate increase cancer cell "stemness," driving recurrence, metastasis and poor clinical outcome in breast cancer: achieving personalized medicine via metabolo-genomics. Cell Cycle. 2011;10(8):1271-86. https://doi.org/10.4161/cc.10.8.15330.

17. (EPOC) CEPaOoC. What study designs can be considered for inclusion in an EPOC review and what should they be called? EPOC resources for review authors, 2020. 2020.

18. (SIGN). SIGN. Methodology checklist 2: controlled trials. 2014.

19. Sterne JAC, Savović J, Page MJ, et al. RoB 2. A revised tool for assessing risk of bias in randomised trials. BMJ. 2019;366:14898. https://doi.org/10.1136/bmj.14898.

20. Bozzetti F, Gavazzi C, Mariani L, Crippa F. Glucose-based total parenteral nutrition does not stimulate glucose uptake by humans tumours. Clin Nutr. 2004;23(3):417-21. https://doi.org/10.1016/j. clnu.2003.09.012.

21. Artzi M, Liberman G, Vaisman N, et al. Changes in cerebral metabolism during ketogenic diet in patients with primary brain tumors: (1)H-MRS study. J Neurooncol. 2017;132(2):267-75. https://doi.org/10.1007/s11060-016-2364-x.

22. Higgins JPT TJ, Chandler J, Cumpston M, Li T, Page MJ, Welch VA, editors. Cochrane handbook for systematic reviews of interventions version 6.1 (updated September 2020). Cochrane, 2020. 2020.

23. Khodabakhshi A, Akbari ME, Mirzaei HR, Mehrad-Majd H, Kalamian M, Davoodi SH. Feasibility, safety, and beneficial effects of MCT-based ketogenic diet for breast cancer treatment: a randomized controlled trial study. Nutr Cancer. 2020;72(4):627-34. https://doi.org/10.1080/01635581.2019.1650942.

24. Freedland SJ, Allen J, Jarman A, et al. A randomized controlled trial of a 6-month low-carbohydrate intervention on disease progression in men with recurrent prostate cancer: carbohydrate and prostate study 2 (CAPS2). Clin Cancer Res. 2020;26(12):303543. https://doi.org/10.1158/1078-0432.Ccr-19-3873. 
25. Strowd RE, Cervenka MC, Henry BJ, Kossoff EH, Hartman AL, Blakeley JO. Glycemic modulation in neuro-oncology: experience and future directions using a modified Atkins diet for high-grade brain tumors. Neurooncol Pract. 2015;2(3):127-36. https://doi. org/10.1093/nop/npv010.

26. Iyikesici MS. Feasibility study of metabolically supported chemotherapy with weekly carboplatin/paclitaxel combined with ketogenic diet, hyperthermia and hyperbaric oxygen therapy in metastatic non-small cell lung cancer. Int J Hyperthermia. 2019;36(1):446-55. https://doi.org/10.1080/02656736.2019. 1589584 .

27. Iyikesici MS. Long-term survival outcomes of metabolically supported chemotherapy with gemcitabine-based or FOLFIRINOX regimen combined with ketogenic diet, hyperthermia, and hyperbaric oxygen therapy in metastatic pancreatic cancer. Complement Med Res. 2020;27(1):31-9. https://doi.org/10.1159/000502135.

28. Woodhouse C, Ward T, Gaskill-Shipley M, Chaudhary R. Feasibility of a modified Atkins diet in glioma patients during radiation and its effect on radiation sensitization. Curr Oncol. 2019;26(4):e433-8. https://doi.org/10.3747/co.26.4889.

29. van der Louw E, Olieman JF, van den Bemt P, et al. Ketogenic diet treatment as adjuvant to standard treatment of glioblastoma multiforme: a feasibility and safety study. Ther Adv Med Oncol. 2019;11:1758835919853958. https://doi.org/10.1177/1758835919 853958.

30. Rieger J, Bähr O, Maurer GD, et al. ERGO: a pilot study of ketogenic diet in recurrent glioblastoma. Int $\mathrm{J}$ Oncol. 2014;44(6):1843-52. https://doi.org/10.3892/ijo.2014.2382.

31. Fine EJ, Segal-Isaacson CJ, Feinman RD, et al. Targeting insulin inhibition as a metabolic therapy in advanced cancer: a pilot safety and feasibility dietary trial in 10 patients. Nutrition. 2012;28(10):1028-35. https://doi.org/10.1016/j.nut.2012.05.001.

32. Cohen CW, Fontaine KR, Arend RC, Soleymani T, Gower BA. Favorable effects of a ketogenic diet on physical function, perceived energy, and food cravings in women with ovarian or endometrial cancer: a randomized, controlled trial. Nutrients. 2018. https://doi.org/10.3390/nu10091187.

33. Klement RJ, Schäfer G, Sweeney RA. A ketogenic diet exerts beneficial effects on body composition of cancer patients during radiotherapy: an interim analysis of the KETOCOMP study. J Tradit Complement Med. 2020;10(3):180-7. https://doi.org/10. 1016/j.jtcme.2019.03.007.

34. Ok JH, Lee H, Chung HY, et al. The potential use of a ketogenic diet in pancreatobiliary cancer patients after pancreatectomy. Anticancer Res. 2018;38(11):6519-27. https://doi.org/10.21873/ anticanres.13017.

35. Martin-McGill K, Cherry G, Marson A, Smith CT, Jenkinson M. Ketogenic diets as an adjuvant therapy in glioblastoma (KEATING): a mixed method approach to assessing trial feasibility. Neuro Oncol. 2018. https://doi.org/10.1093/neuonc/noy148.

36. Schmidt M, Pfetzer N, Schwab M, Strauss I, Kammerer U. Effects of a ketogenic diet on the quality of life in 16 patients with advanced cancer: a pilot trial. Nutr Metab. 2011;8(1):54. https://doi.org/10.1186/1743-7075-8-54.

37. Tan-Shalaby JL, Carrick J, Edinger K, et al. Modified Atkins diet in advanced malignancies-final results of a safety and feasibility trial within the Veterans Affairs Pittsburgh Healthcare System. Nutr Metab (Lond). 2016;13:52. https://doi.org/10.1186/ s12986-016-0113-y.

38. Zahra A, Fath MA, Opat E, et al. Consuming a ketogenic diet while receiving radiation and chemotherapy for locally advanced lung cancer and pancreatic cancer: the University of Iowa experience of two phase 1 clinical trials. Radiat Res. 2017;187(6):74354. https://doi.org/10.1667/rr14668.1.

39. Schwartz K, Chang HT, Nikolai M, et al. Treatment of glioma patients with ketogenic diets: report of two cases treated with an IRB-approved energy-restricted ketogenic diet protocol and review of the literature. Cancer Metab. 2015;3:3. https://doi.org/ 10.1186/s40170-015-0129-1.

40. Nebeling LC, Miraldi F, Shurin SB, Lerner E. Effects of a ketogenic diet on tumor metabolism and nutritional status in pediatric oncology patients: two case reports. J Am Coll Nutr. 1995;14(2):202-8. https://doi.org/10.1080/07315724.1995.10718 495.

41. Klement RJ, Sweeney RA. Impact of a ketogenic diet intervention during radiotherapy on body composition: I. Initial clinical experience with six prospectively studied patients. BMC Res Notes. 2016;9:143. https://doi.org/10.1186/s13104-016-1959-9.

42. Cohen CW, Fontaine KR, Arend RC, et al. A ketogenic diet reduces central obesity and serum insulin in women with ovarian or endometrial cancer. J Nutr. 2018;148(8):1253-60. https://doi. org/10.1093/jn/nxy119.

43. Rossi-Fanelli F, Franchi F, Mulieri M, et al. Effect of energy substrate manipulation on tumour cell proliferation in parenterally fed cancer patients. Clin Nutr. 1991;10(4):228-32. https://doi.org/10. 1016/0261-5614(91)90043-c.

44. Fearon KC, Borland W, Preston T, Tisdale MJ, Shenkin A, Calman KC. Cancer cachexia: influence of systemic ketosis on substrate levels and nitrogen metabolism. Am J Clin Nutr. 1988;47(1):42-8. https://doi.org/10.1093/ajcn/47.1.42.

45. Champ CE, Palmer JD, Volek JS, et al. Targeting metabolism with a ketogenic diet during the treatment of glioblastoma multiforme. J Neurooncol. 2014;117(1):125-31. https://doi.org/10. 1007/s11060-014-1362-0.

46. Zuccoli G, Marcello N, Pisanello A, et al. Metabolic management of glioblastoma multiforme using standard therapy together with a restricted ketogenic diet: case report. Nutr Metab (Lond). 2010;7:33. https://doi.org/10.1186/1743-7075-7-33.

47. Tóth C, Clemens Z. Treatment of rectal cancer with the paleolithic ketogenic diet: a 24-months follow-up. Am J Med Case Rep. 2017;5(8):205-16.

48. Bozzetti F, Cozzaglio L, Gavazzi C, et al. Total nutritional manipulation in humans: report of a cancer patient. Clin Nutr. 1996;15(4):207-9. https://doi.org/10.1016/s0261-5614(96) 80243-3.

49. Martin-McGill KJ, Marson AG, Tudur Smith C, Jenkinson MD. The Modified ketogenic diet in adults with glioblastoma: an evaluation of feasibility and deliverability within the national health service. Nutr Cancer. 2018;70(4):643-9. https://doi.org/10.1080/ 01635581.2018 .1460677$.

50. Moore K. Using the restricted ketogenic diet for brain cancer management: comments from neuro-oncologist. In: Seyfried TN, editor. Cancer as a metabolic disease: on the origin, management, and prevention of cancer. Hoboken: Wiley; 2012. p. 397-400.

51. Klement R, Brehm N, Sweeney R. Ketogenic diets in medical oncology: a systematic review with focus on clinical outcomes. Med Oncol. 2020;37:14. https://doi.org/10.1007/ s12032-020-1337-2.

52. Ryan AM, Power DG, Daly L, Cushen SJ, Ní Bhuachalla Ē, Prado CM. Cancer-associated malnutrition, cachexia and sarcopenia: the skeleton in the hospital closet 40 years later. Proc Nutr Soc. 2016;75(2):199-211. https://doi.org/10.1017/s00296651150041 $9 \mathrm{x}$.

53. Bruggeman AR, Kamal AH, LeBlanc TW, Ma JD, Baracos VE, Roeland EJ. Cancer cachexia: beyond weight loss. J Oncol Pract. 2016;12(11):1163-71. https://doi.org/10.1200/jop.2016.016832.

54. Jansen N, Walach $\mathrm{H}$. The development of tumours under a ketogenic diet in association with the novel tumour marker TKTL1: a case series in general practice. Oncol Lett. 2016;11(1):584-92. https://doi.org/10.3892/ol.2015.3923.

55. Schwalb M, Taubmann M, Hines S, Reinwald H, Ruggiero M. Clinical observation of a novel, complementary, 
immunotherapeutic approach based on ketogenic diet, chondroitin sulfate, vitamin D3, oleic acid and a fermented milk and colostrum product. Am J Immunol. 2016;12:91-8. https://doi.org/10. 3844/ajisp.2016.91.98.

56. Cohen CW, Fontaine KR, Arend RC, Gower BA. A ketogenic diet is acceptable in women with ovarian and endometrial cancer and has no adverse effects on blood lipids: a randomized. Control Trial Nutr Cancer. 2019. https://doi.org/10.1080/01635581.2019.16458 64.

57. Branca JJ, Pacini S, Ruggiero M. Effects of pre-surgical vitamin $\mathrm{D}$ supplementation and ketogenic diet in a patient with recurrent breast cancer. Anticancer Res. 2015;35(10):5525-32.

58. Schroeder U, Himpe B, Pries R, Vonthein R, Nitsch S, Wollenberg B. Decline of lactate in tumor tissue after ketogenic diet: in vivo microdialysis study in patients with head and neck cancer. Nutr Cancer. 2013;65(6):843-9. https://doi.org/10.1080/01635581. 2013.804579.

59. Elsakka AMA, Bary MA, Abdelzaher E, et al. Management of glioblastoma multiforme in a patient treated with ketogenic metabolic therapy and modified standard of care: a 24-month follow-up. Front Nutr. 2018;5:20. https://doi.org/10.3389/fnut. 2018.00020

60. Brünings W. Beitraege zum Krebsproblem. 1. Mitteilung: Ueber eine diaetetisch-hormonale Beeinflussung des Krebses. Muenchener Medizinische Wochenschrift. 1941;117-23.

61. Brünings W. Beitraege zum Krebsproblem. 2. Mitteilung: Klinische Anwendungen der diaetetisch-hormonalen Krebsbeeinflussung ("Entzuckerungsmethode"). Muenchener Medizinische Wochenschrift. 1942;71-6.

62. Schulte G, Schütz H. Insulin in der Krebsbehandlung. Muenchener Medizinische Wochenschrift. 1942;648-50.

Publisher's Note Springer Nature remains neutral with regard to jurisdictional claims in published maps and institutional affiliations. 